\title{
DELIMITACIÓN TAXONÓMICA DE ARBUTUS MOLLIS Y A. OCCIDENTALIS (ERICACEAE)
}

\author{
M. Socorro GonzÁlez-Elizondo ${ }^{1,3}$, Martha GonzÁlez-Elizondo ${ }^{1}$ y Sergio \\ ZAMUDIO $^{2}$
}

${ }^{1}$ Instituto Politécnico Nacional, Centro Interdisciplinario de Investigación para el Desarrollo Integral Regional, Unidad Durango, Sigma 119, Fracc. 20 de

Noviembre II, 34220 Durango, Durango, México.

${ }^{2}$ Instituto de Ecología, A.C., Centro Regional del Bajío

Apdo. postal 386, 61600 Pátzcuaro, Michoacán, México.

${ }^{3}$ Autor para la correspondencia: herbario_ciidir@yahoo.com.mx

\section{RESUMEN}

Arbutus mollis Kunth in H.B.K., tradicionalmente considerado como un sinónimo de A. xalapensis Kunth in H.B.K., es el nombre más antiguo para las plantas conocidas como $A$. occidentalis var. villosa McVaugh \& Rosatti. La revisión de los madroños de porte arbustivo que han sido incluidos bajo el nombre de $A$. occidentalis McVaugh \& Rosatti revela que las dos variedades descritas para esa especie, posteriormente reducidas a sinonimia, difieren en varios caracteres morfológicos que sugieren un origen a partir de diferentes linajes, lo que justifica su separación a nivel de especie, por lo que $A$. mollis es reconocida como taxon independiente. El hábito arbustivo compartido por A. mollis y A. occidentalis probablemente representa un caso de evolución convergente. Con base en la nueva delimitación de A. mollis y de $A$. occidentalis se presentan descripciones enmendadas de ambas, así como una clave para separarlas. Los aparentes intermedios representan ya sea variantes morfológicas, híbridos, retoños de tocones de árboles después del corte o del fuego, o rara vez formas arbustivas de otras especies. Se comentan algunas de las variantes morfológicas y se documentan los siguientes híbridos: Arbutus mollis x A. tessellata (Guanajuato y Michoacán), Arbutus mollis x A. xalapensis (Querétaro), Arbutus occidentalis x A. arizonica (Durango, Aguascalientes y Jalisco), Arbutus occidentalis x A. tessellata (Jalisco), Arbutus occidentalis x Arbutus bicolor (Chihuahua y Durango) y Arbutus occidentalis $\mathrm{x}$ Arbutus aff. xalapensis (Durango y Jalisco).

Palabras clave: Arbutus xalapensis, híbridos, introgresión, madroño, sistemática, variantes morfológicas. 


\section{ABSTRACT}

Arbutus mollis Kunth in H.B.K. treated since long ago as a synonym of A. xalapensis Kunth in H.B.K. is the correct name for the plants formerly treated as A. occidentalis var. villosa McVaugh \& Rosatti. A revision of the complex of A. occidentalis McVaugh \& Rosatti reveals that the two varieties originally described for that species differ in characters of foliage, indument and inflorescence, which suggests an origin from different lineages and justify their separation to the species level, and therefore A. mollis is recognized here as an independent species. The shrubby habit shared by A. mollis and A. occidentalis is probably a case of convergent evolution. The taxonomic reinstatement of $A$. mollis is made and amended descriptions for $A$. mollis and $A$. occidentalis and a key to distinguish them are given. Apparent intermediates are either morphs, hybrids, stump sprouts of tree species after fire or cutting, or rarely shrubby forms of other species. The following hybrids are documented: Arbutus mollis x A. tessellata (Guanajuato and Michoacán), Arbutus mollis x A. xalapensis (Querétaro), Arbutus occidentalis x A. arizonica (Durango, Aguascalientes, and Jalisco), Arbutus occidentalis $\mathrm{x}$ A. tessellata (Jalisco), Arbutus occidentalis $\mathrm{x}$ Arbutus bicolor (Chihuahua and Durango), and Arbutus occidentalis x Arbutus aff. xalapensis (Durango and Jalisco).

Key words: Arbutus xalapensis, hybrids, introgression, madrone, morphs, systematics.

El género Arbutus L. (Ericaceae) constituye un importante componente en algunos bosques templados del Hemisferio Norte. En México presenta su mayor diversificación, con siete de las 11 especies conocidas a nivel mundial. Debido a la gran variación morfológica de algunas de estas, el concepto de especie en Arbutus ha sido tradicionalmente muy amplio y algunas como A. xalapensis Kunth in H.B.K. y A. occidentalis McVaugh \& Rosatti se han interpretado como taxa particularmente polimórficos. Estos son un buen ejemplo de grupos en los que resulta difícil la aplicación de conceptos de especie, cuya correcta interpretación es de gran interés para entender los patrones y procesos de la evolución (McDade, 1995), de manera que la comprensión de la identidad de los componentes del complejo aquí estudiado tiene importancia desde el punto de vista florístico, taxonómico y evolutivo. Es bien sabido que muchas especies de plantas se pueden diferenciar a pesar de que mantienen cierto intercambio genético con otras (Lexer y Widmer, 2008; Mallet, 2008). El concepto de cohesión (Templeton, 1998), que combina aspectos de reconocimiento con otros ecológicos y genealógicos, ha sido aplicado incluso en grupos como los 
encinos, en los que son comunes la hibridación y el flujo de genes. El concepto de especie adoptado en este trabajo, modificado de las propuestas presentadas por Hausdorf (2011), es el de conjuntos fenéticos que mantienen su diferenciación a pesar de tener ocasional entrecruzamiento reproductivo con otros grupos.

Durante el tratamiento de Ericaceae para la Flora del Bajío y regiones adyacentes, se encontró que los Arbutus de porte arbustivo que crecen en las cercanías de la ciudad de Guanajuato, México, la localidad tipo de $A$. mollis Kunth in H.B.K., no corresponden a un sinónimo de $A$. xalapensis, como tradicionalmente se ha aceptado, sino que forman parte de lo que ha sido considerado como A. occidentalis var. villosa McVaugh \& Rosatti y, por lo tanto, Arbutus mollis es el nombre más antiguo que debe aplicarse a ese grupo de plantas. La revisión taxonómica de las plantas que han sido consideradas como parte de Arbutus occidentalis reveló que bajo ese nombre se han incluido a algunas que comparten el hábito arbustivo pero que difieren en varios aspectos, y que las dos variedades descritas por McVaugh y Rosatti ( $\mathrm{A}$. occidentalis var. occidentalis y A. occidentalis var. villosa) y posteriormente reducidas a sinonimia por Sørensen (1995), representan en realidad dos taxa independientes, a los que se reconoce aquí con la categoría de especie.

\section{La identidad de Arbutus mollis}

Arbutus mollis fue descrita por Kunth en la obra Nova genera et species plantarum (quarto ed., p. 280), publicada en 1819, a partir de colectas realizadas por Humboldt y Bonpland en las cercanías de la ciudad de Guanajuato. Debido a que el tipo de A. mollis, supuestamente en el herbario P, no ha sido localizado, Sørensen (1995) lectotipificó a la especie con su descripción original y consideró (op. cit.: 209) que la descripción de A. mollis se aplica muy bien a una forma de A. xalapensis con pubescencia suave al tacto (Sørensen, com. pers.). Basado en esto, y en el hecho de que Kunth estableció, al final de la descripción de A. mollis, que el espécimen era "similar al anterior" (es decir, a A. xalapensis, descrita justo antes que A. mollis), Sørensen consideró que $A$. mollis era un sinónimo de $A$. xalapensis, como lo había hecho Standley desde 1924 y posteriormente Luteyn en 2009.

A continuación se presenta una transcripción de la diagnosis y la descripción de Arbutus mollis:

"foliis oblongis, acutis, argute dentatis, coriaceis, supra molliter pubescentibus, subtus canescenti-tomentosis; racemis paniculatis". 
"Rami sparsi; ramuli purpurascenti-fusci, angulati, pubescentes. Folia sparsa, petiolata, oblonga, acuta, basi rotundata, argute-dentata, reticulato-venosa, nervo medio subtus prominente, coriacea, supra molliter pubescentia et viridia, subtus canescenti-tomentosa, 24-30 lineas longa, 10-12 lineas lata. Petioli 6-8 lineas longi, semiteretes, pubescentes. Paniculae terminales, sessiles, subbipollicares; ramis coarctatis; aut si mavis, racemi complures in apice ramulorum paniculato-congesti, abbreviati. Flores pedicellati, approximati, cernui, magnitudine et structura prorsus praecedentis. Pedicelli duas lineas longi rhachisque canescenti-tomentosa. Bracteae tres ad basim pedicelli; interior ovata, acutiuscula, concava, externe canescentipubescens, pedicellum longitudine subaequans; duae interiores dimidio breviores, oppositae, ovatae, acutae, concavae, diaphanae, puberulae. Praecedenti simillima".

Aunque la línea final de la descripción de $A$. mollis sugiere similitud con $A$. xalapensis, la única parte en donde explícitamente se indica similitud entre ambas es en relación con el tamaño y estructura de las flores, un carácter relativamente poco diverso en Arbutus y en general en Arbuteae, donde la estructura floral ha tenido muy poca divergencia evolutiva (Diggs, 1995). La comparación de la descripción original de $A$. mollis con materiales recolectados recientemente en el estado de Guanajuato, muestra que ésta coincide bien con las plantas de porte arbustivo bajo con hojas coriáceas relativamente pequeñas, con pubescencia suave al tacto, y con inflorescencias compactas (Fig. 1), que crecen en las cercanías de la ciudad de Guanajuato, una de las localidades visitadas por Humboldt y Bonpland y en cambio no se ajusta a las características de A. xalapensis. Esta última, por su parte, en Guanajuato se encuentra restringida al extremo noreste del estado, en una zona que no fue visitada por dichos exploradores, cuyas colectas se llevaron a cabo en las cercanías de la ciudad de Guanajuato, Santa Rosa, Celaya y Salamanca (J. Rzedowski, com. pers.).

La descripción original de A. mollis indica que la planta crece cerca de Guanajuato, a $2300 \mathrm{~m}$ de altitud. Sin embargo, actualmente en las cercanías de dicha ciudad la vegetación a esta elevación está constituida por una mezcla de elementos de bosque tropical caducifolio y de matorral xerófilo en donde no se desarrolla ninguna especie de Arbutus, mientras que los bosques de encino donde crece A. mollis se desarrollan a partir de $2500 \mathrm{~m}$ de altitud. La elevación registrada por Humboldt y Bonpland podría reflejar un error, situación muy improbable, ya que el equipo geográfico de la expedición era de gran precisión y entre sus actividades se contaba la de documentar la elevación de varios picos montañosos; o bien, ser correcta y representar un ejemplo más de la retracción que los bosques templados están sufriendo hacia mayores elevaciones como resultado tanto del disturbio antropogénico como del cambio climático. 

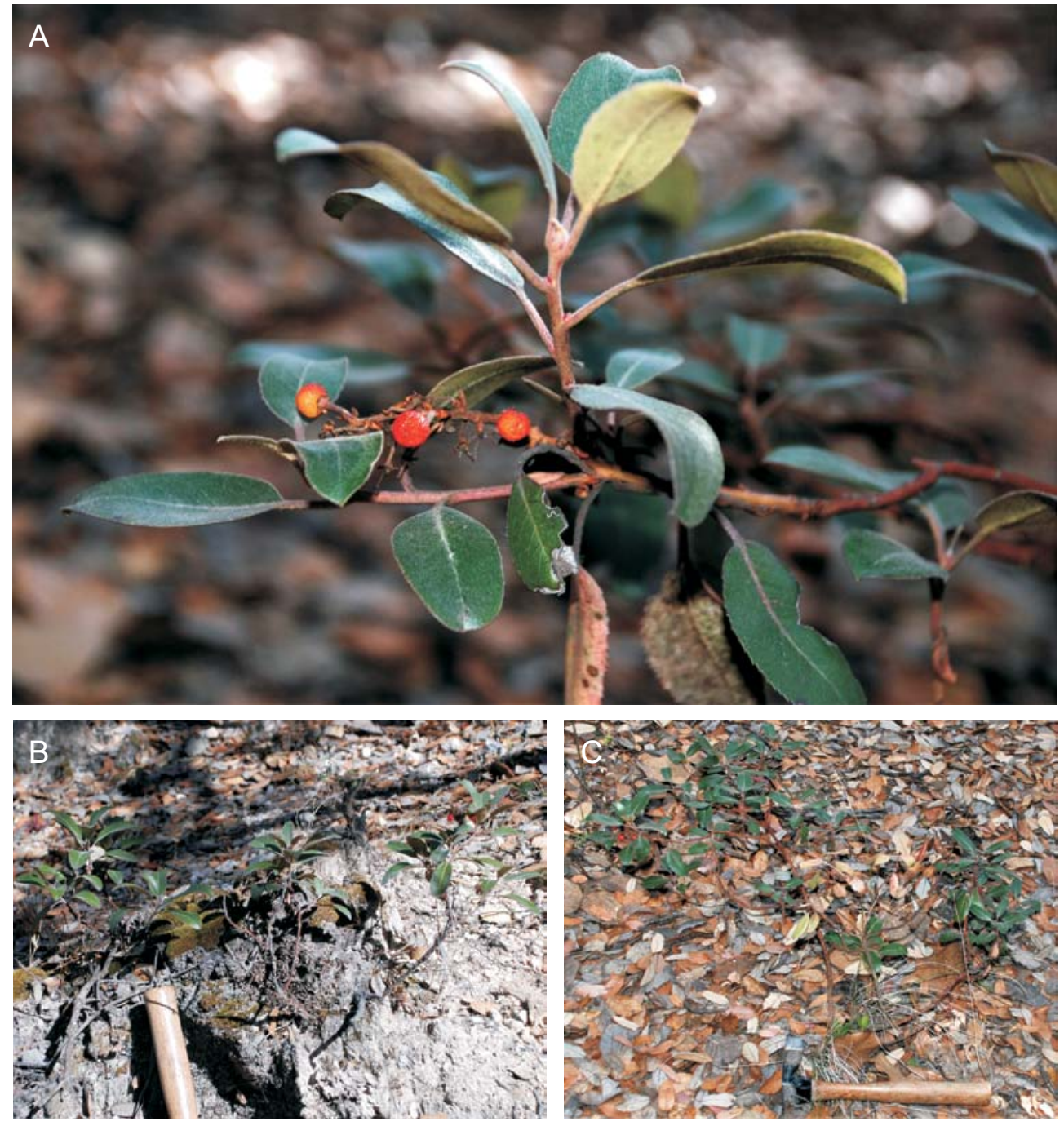

Fig. 1. Arbutus mollis de localidad tipo en Guanajuato: A. ramilla con frutos (Zamudio 15401); B. hábito (Zamudio 15401-b); C. hábito (Zamudio 15401).

Las descripciones en Nova genera et species plantarum no eran particularmente precisas. Por ejemplo, para A. xalapensis las hojas fueron dadas a conocer como "bipollicaria et paulo longiora, pollicem lata", pero esa especie tiene hojas más grandes que los aprox. $5 \mathrm{~cm}$ y más de largo y $2.5 \mathrm{~cm}$ de ancho registrados en 
la descripción. Sin embargo, en el caso de la descripción de A. mollis, las medidas fueron dadas de manera más precisa que para A. xalapensis, y se consideran de mayor confiabilidad. Además, a pesar de que las plantas de A. xalapensis que se encuentran en el noreste de Guanajuato presentan hojas relativamente pequeñas con respecto al promedio de las de esa especie, sus medidas superan a las de las hojas y peciolos descritos para A. mollis, dado que en A. xalapensis las hojas son de 6.5 a $11.3 \mathrm{~cm}$ de largo y (2.5-)3.5 a $6.2 \mathrm{~cm}$ de ancho y los peciolos de (1.5-)1.7 a $3.1 \mathrm{~cm}$ de largo, mientras que en $A$. mollis las hojas van de 5.5 a $7 \mathrm{~cm}$ de largo y de 2.3 a $2.8 \mathrm{~cm}$ de ancho y los peciolos de 1.4 a $1.8 \mathrm{~cm}$ de largo. Adicionalmente, A. xalapensis son árboles de 4 a $10 \mathrm{~m}$ de alto en el NE de Guanajuato, con hojas ovadas, redondeadas a cordadas en la base y con flores blancas, verdosas o amarillas. Estas discrepancias y el hecho de que en las áreas visitadas por Humboldt y Bonpland en Guanajuato no se encuentren plantas que coincidan con las características de $A$. xalapensis, indican que $A$. mollis representa una especie distinta.

Aunque muchas de las características descritas para A. mollis son comunes a diferentes especies de Arbutus, otras, como el tamaño y la consistencia coriácea de las hojas y el tipo de pubescencia, son propias de las plantas arbustivas de las cercanías de Guanajuato. Características adicionales de esas plantas son el porte arbustivo bajo ( 0.2 a $0.5 \mathrm{~m}$ de alto); brácteas exteriores de 2.8 a $3.6 \mathrm{~mm}$ de largo y 2.4 a $3.6 \mathrm{~mm}$ de ancho, las interiores de 1.3 a $1.8 \mathrm{~mm}$ de largo y de $0.6 \mathrm{a} 1.4 \mathrm{~mm}$ de ancho; lóbulos del cáliz (en fruto) de 1 a $1.8 \mathrm{~mm}$ de largo; y frutos con (1)2 a 4(8) semillas por lóculo. Estos rasgos también coinciden con las plantas que han sido tratadas como A. occidentalis var. villosa, de manera que siguiendo el principio de prioridad el nombre correcto para este taxon es Arbutus mollis (Fig. 2 A, 2 B; 3 A, 3 B).

\section{Arbutus mollis y A. occidentalis}

Arbutus occidentalis fue descrita por McVaugh y Rosatti (1978) con dos variedades morfológica y geográficamente separadas. Posteriormente, A. occidentalis var. villosa fue reducida a sinonimia de A. occidentalis por Sørensen (1995), quien argumenta que al inicio de su estudio del complejo de $A$. occidentalis los dos taxa infraespecíficos "parecían claros y distintos", pero que al irse acumulando los especímenes las discontinuidades descritas entre ellos empezaron a empañarse, por lo que llegó a la conclusión de que se trataba de un único y gran taxon polimórfico y decidió no aceptar las variedades. El mismo autor comenta que la variación encontrada en $A$. occidentalis (en el sentido amplio en que él reconoce a la especie) es 

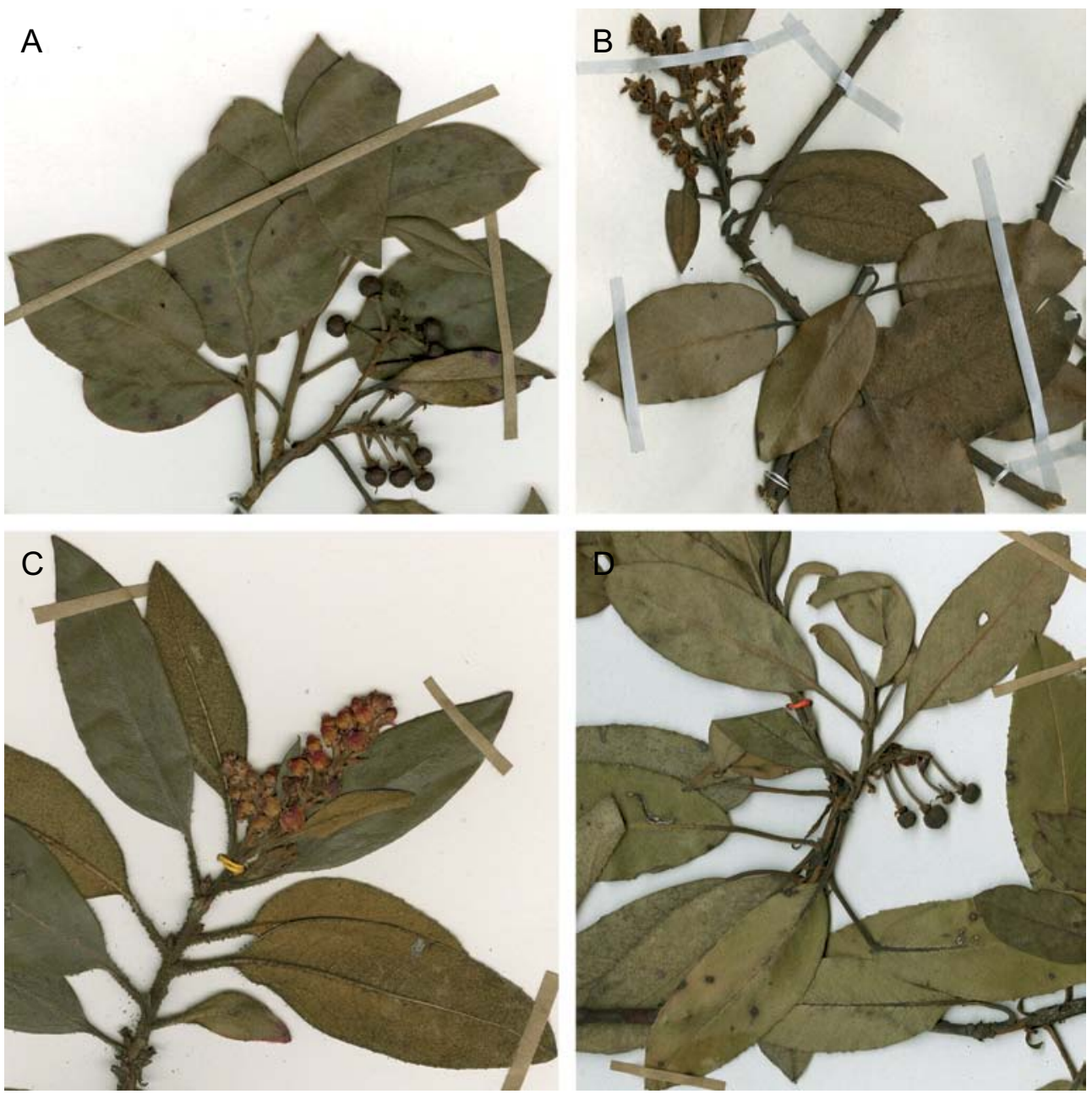

Fig. 2. Arbutus mollis, ramillas con flores o frutos: A. de localidad tipo en Guanajuato (Zamudio y Murillo 6388); B. del Estado de México (isotipo de A. occidentalis var. villosa, Hinton et al. 8847 US); C. variante glandular, Michoacán (Martínez 2003); D. Variante de Durango (González 4571).

comparable a la encontrada en $A$. xalapensis y que con base solamente en caracteres foliares, algunos especímenes no caen claramente en una u otra especie, de manera que el hábito arbustivo es el único caracter que puede ser usado confiablemente para separar a ambas. El alto grado de polimorfismo que existe tanto en el complejo de A. xalapensis como en lo que se ha reconocido como A. occidentalis s.l. fue la razón 

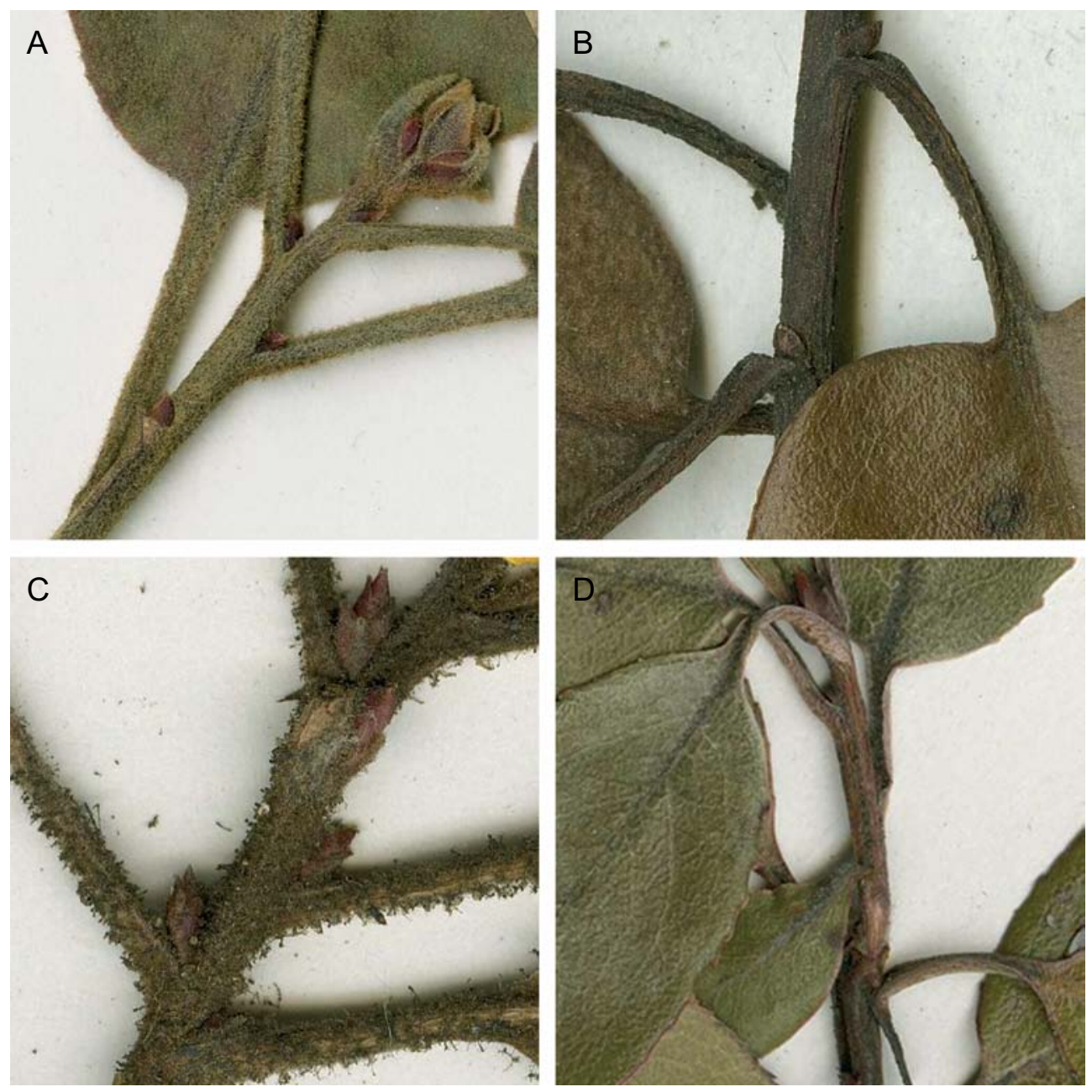

Fig. 3. Ramillas, acercamiento: A. Arbutus mollis (Zamudio y Murillo 6388); B. A. mollis (isotipo de A. occidentalis var. villosa, Hinton et al. 8847 US); C. A. mollis, variante glandular (Martínez 2003); D. A. occidentalis de localidad tipo (Iltis et al. 29390a).

por la que McVaugh y Rosatti (op. cit.) describieran a esta última con temor a equivocarse ("with some trepidation"), a pesar de las notorias diferencias que existen con A. xalapensis.

Por otro lado, el mismo Sørensen (1995) destaca caracteres de A. occidentalis adicionales al hábito arbustivo que pueden colectivamente ayudar al reconocimiento de esa especie: 1) color de la flor, rosadas o blanquecinas con tinte rojizo (vs. 
blancas, blanco-amarillentas o blanco-verdosas en A. xalapensis, excepto en la var. texana con flores a veces rosadas o con tinte rojizo); 2) fruto, que en $A$. occidentalis desarrolla solo una o dos semillas por lóculo, raramente tres (vs. dos a siete semillas por lóculo); 3) brácteas en la base de los pedicelos, que tienden a ser más largas (hasta $6 \mathrm{~mm}$ y casi igualan al pedicelo en la antesis o raramente son incluso más largas que el pedicelo en las especies arbustivas (vs. hasta $4.2 \mathrm{~mm}$ en A. xalapensis), pero el mismo autor menciona que este carácter es difícil de evaluar, ya que la longitud del pedicelo se alarga al madurar el fruto (ver, por ejemplo, Fig. 2 A, 2 B); 4) postura de la flor, con frecuencia péndula en la antesis (vs. ascendente o divaricada en A. xalapensis); y 5) tricomas glandulares, que en A. occidentalis están usualmente presentes sobre los ejes fértiles pero que no son sustancialmente más largos que los tricomas no glandulares (vs. tricomas glandulares más largos que los no glandulares en $A$. xalapensis). Estos caracteres son de utilidad para separar entre A. xalapensis y A. occidentalis sensu stricto, con la excepción de las flores péndulas, que también pueden presentarse en algunas variantes de A. xalapensis (p. ej. en Arbutus texana). Pero algunos de ellos no funcionan para distinguir entre A. xalapensis y lo que se ha considerado como Arbutus occidentalis var. villosa (=A. mollis), que tiene 2 a 4(-8) semillas por lóculo, flores con frecuencia erectas y variantes en las que los tricomas glandulares son notablemente más largos que los no glandulares. Además de los caracteres destacados por Sørensen, otros rasgos que permiten distinguir fácilmente entre A. xalapensis y A. occidentalis son el tamaño de las láminas foliares, peciolos e inflorescencias, así como el número de dientes por centímetro en los márgenes de las hojas.

La revisión de plantas de lo que ha sido considerado como variedades de A. occidentalis o variación morfológica en dicha especie, revela que aunque éstas comparten el hábito arbustivo, pueden diferenciarse en varios caracteres (Cuadro 1), cada uno de los cuales presenta afinidades morfológicas con distintas especies, lo que se confirma con divergencias a nivel micromorfológico en hojas y peciolos (Fig. 4 y 5). Las plantas del norte (oriente de Sinaloa, sur de Chihuahua, Durango, Jalisco y Aguascalientes) representan a $A$. occidentalis, que muestra estrechas semejanzas con Arbutus arizonica (A. Gray) Sarg., mientras que las del sur (sur de Durango; Guanajuato, Michoacán, Hidalgo, Estado de México, Guerrero y Oaxaca) pertenecen a $A$. mollis, la cual está aparentemente más relacionada con A. xalapensis.

Las semejanzas entre $A$. occidentalis y $A$. arizonica son particularmente evidentes en la superficie y color de las ramillas, hojas y peciolos, tanto a nivel morfológico como micromorfológico (Fig. 5 A-D). Ambas especies hibridizan con frecuencia $\mathrm{y}$, en poblaciones en Jalisco y Aguascalientes, se encuentran individuos intermedios 
Acta Botanica Mexicana 101: 49-81 (2012)

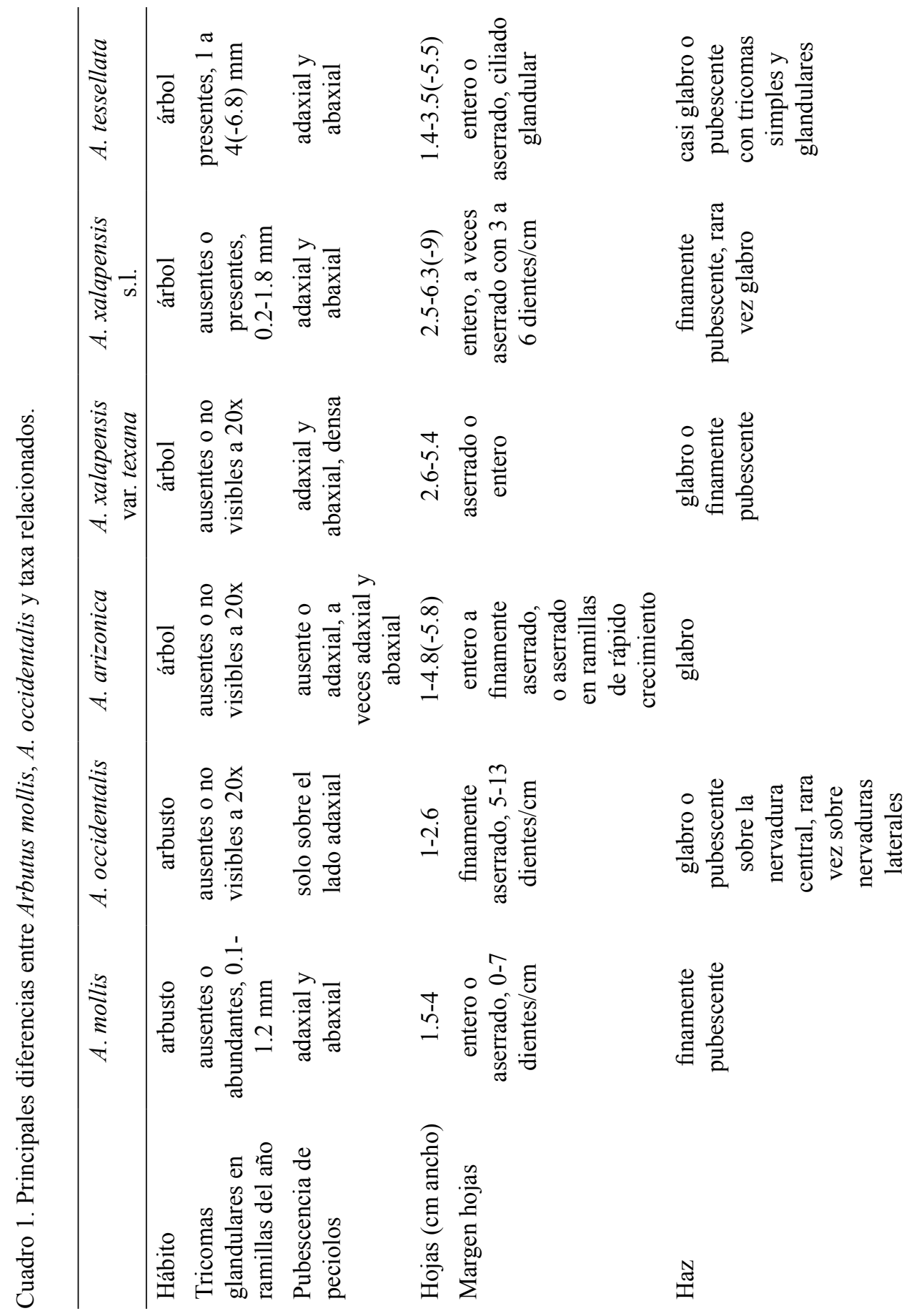


González-Elizondo et al.: Delimitación taxonómica de Arbutus mollis y Arbutus occidentalis

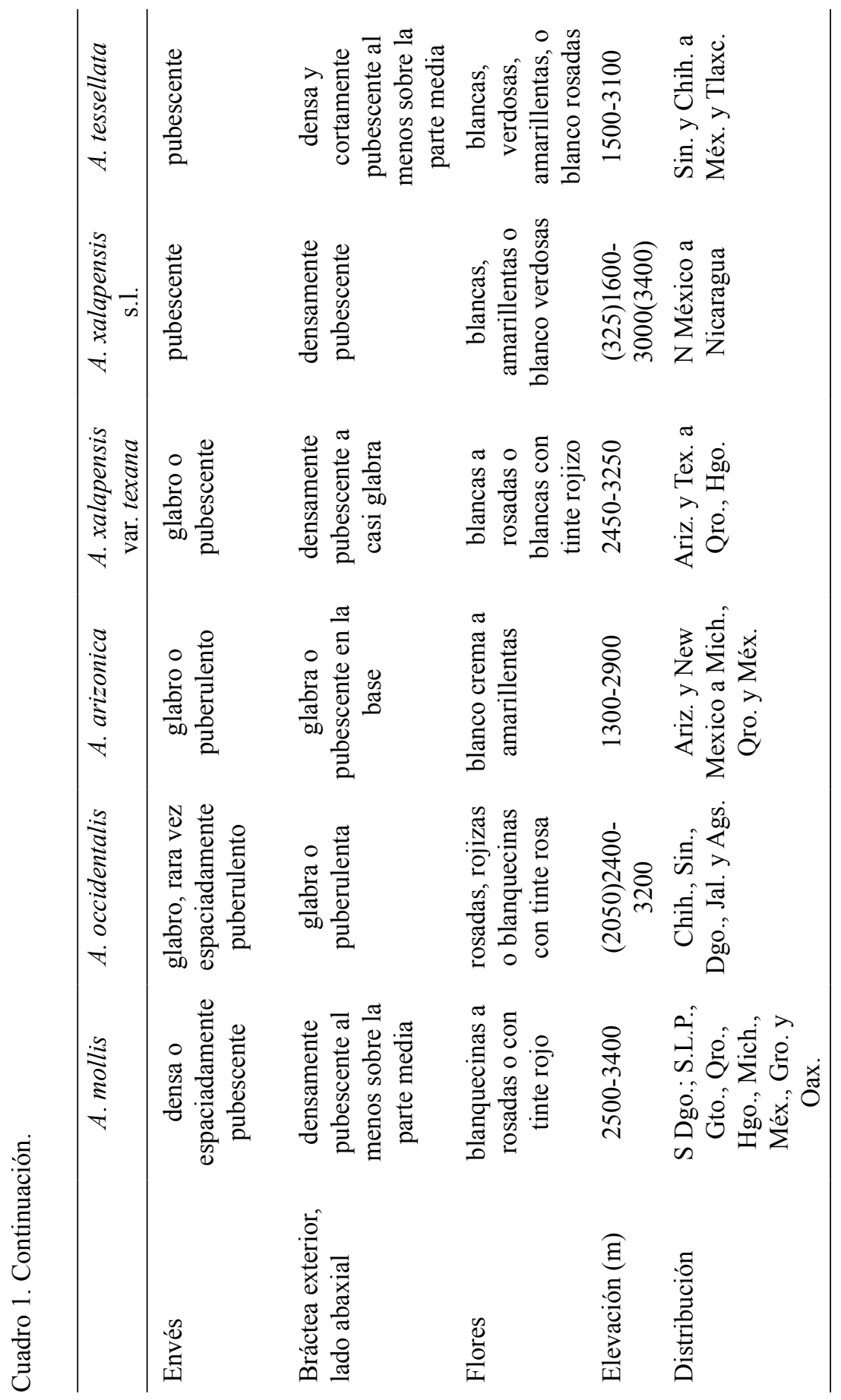



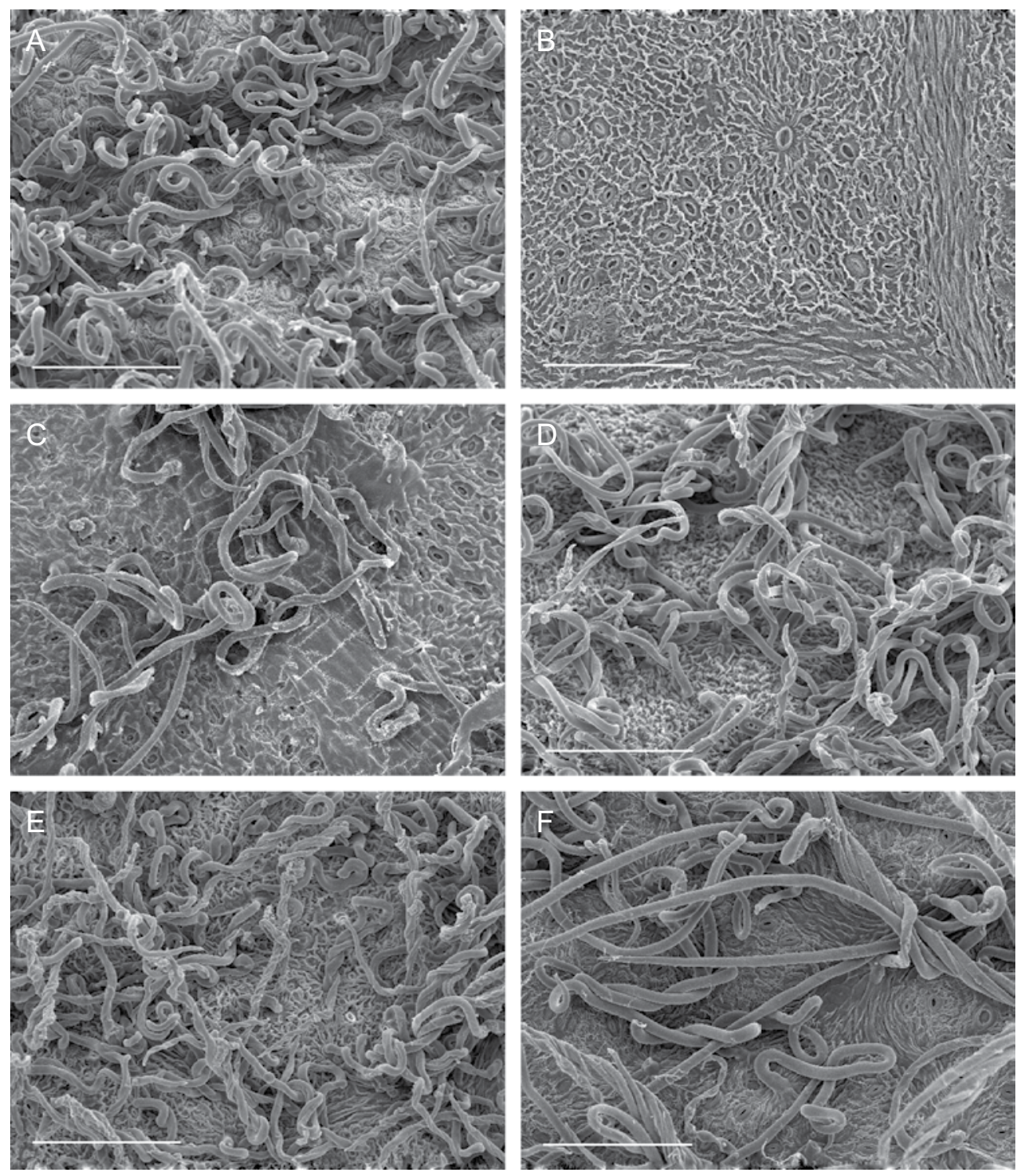

Fig. 4. Superficie abaxial de la hoja: A. Arbutus mollis Guanajuato (Zamudio y González 11356); B. A. occidentalis Durango (González 4842a); C. A. mollis glandular Michoacán (Zamudio y Díaz Barriga 5156); D. A. mollis Durango (González 4571); E. A. occidentalis x Arbutus bicolor (González 2446); F. A. occidentalis x A. xalapensis (González 6468). Imágenes a través de microscopio electrónico de barrido tomadas sobre el tercio proximal de la hoja, entre la nervadura central y el margen. Barra de escala $=0.2 \mathrm{~mm}$. 
González-Elizondo et al.: Delimitación taxonómica de Arbutus mollis y Arbutus occidentalis
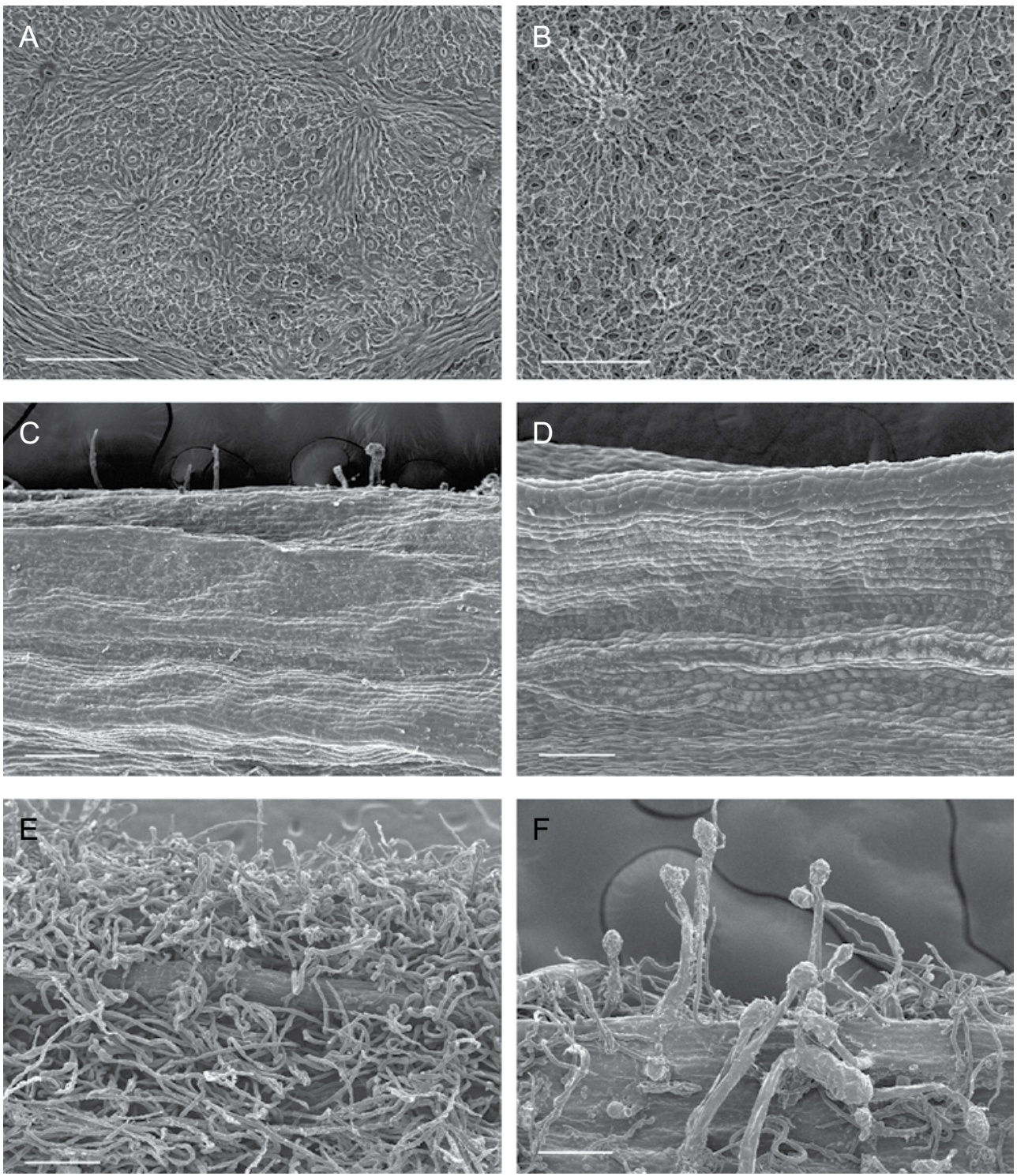

Fig. 5. Superficie abaxial de la hoja: A. A. occidentalis (González 6233); B. A. arizonica (González 6278). Peciolo, lado abaxial: C. A. occidentalis (González 4842a); D. A. arizonica (González 6278); E. A. mollis (Zamudio y Murillo 6388); F. A. mollis glandular (Zamudio y Díaz Barriga 5156). Imágenes a través de microscopio electrónico de barrido. Barra de escala $=0.2 \mathrm{~mm}$. 
difícilmente asignables a una u otra (Fig. 6 C), lo que indica una estrecha relación. En otras poblaciones ubicadas en Durango, Aguascalientes y Jalisco se encuentran individuos achaparrados de $A$. arizonica que han sido erróneamente identificados como A. occidentalis, que crece en el mismo sitio. Ocasionalmente los arbustos postrados con hojas y peciolos pequeños (rasgos de $A$. occidentalis) producen ramas ascendentes con follaje de aspecto muy similar al de $A$. arizonica, revelando posible introgresión genética. Datos moleculares (Hileman et al., 2001) también indican una estrecha relación entre ambas especies, ya que forman parte del mismo clado.

En cambio, para A. mollis, de acuerdo con las evidencias morfológicas (Cuadro 1), la relación más cercana debe ser con A. xalapensis. Así, aunque $A$. mollis y $A$. occidentalis comparten el hábito arbustivo, parecen estar menos relacionadas entre sí que con otras especies de Arbutus y tal forma biológica podría representar un caso de evolución convergente. Por lo anterior, Arbutus mollis es reconocida como especie independiente de $A$. occidentalis. Un problema similar en complejos de taxa con circunscripción no resuelta fue estudiado por Soubani (2010), quien con base en datos moleculares en Helianthemum encontró que las subespecies que habían sido reconocidas con apoyo en la morfología incluyen elementos polifiléticos y que la evolución paralela en poblaciones regionales produce morfologías similares sin que éstas necesariamente estén cercanamente relacionadas.

Arbutus occidentalis y A. mollis pueden ser separadas mediante la siguiente clave (modificada de McVaugh \& Rosatti, 1978):

1. Hojas con envés glabro o rara vez puberulento, haz glabro o pubescente sobre la nervadura central, rara vez sobre nervaduras laterales, margen fina y uniformemente aserrado con 5-13 dientes/cm; peciolo pubescente solo en el lado adaxial; inflorescencia con tricomas glandulares inconspicuos o ausentes, brácteas lustrosas, glabras o puberulentas exteriormente excepto por el margen ciliado a ciliado-glandular; parte distal del pedicelo glabra o con tricomas blancos poco rizados; conocida del sur de Chihuahua y oriente de Sinaloa a Jalisco

A. occidentalis

1. Hojas con envés densa o espaciadamente lanoso-velloso, haz fina y espaciadamente pubescente, margen entero o con 0-7 dientes/cm; peciolo pubescente adaxial y abaxialmente; inflorescencia con numerosos tricomas glandulares conspicuos o inconspicuos, de 0.1 a $1.2 \mathrm{~mm}$ de longitud, brácteas opacas, rara vez lustrosas, densamente pubescentes por fuera con tricomas crespos y a veces glandular pubescentes; parte distal del pedicelo densamente pubescente con tricomas rizados; conocida del sur de Durango a Guerrero y Oaxaca ....... A. mollis 
González-Elizondo et al.: Delimitación taxonómica de Arbutus mollis y Arbutus occidentalis
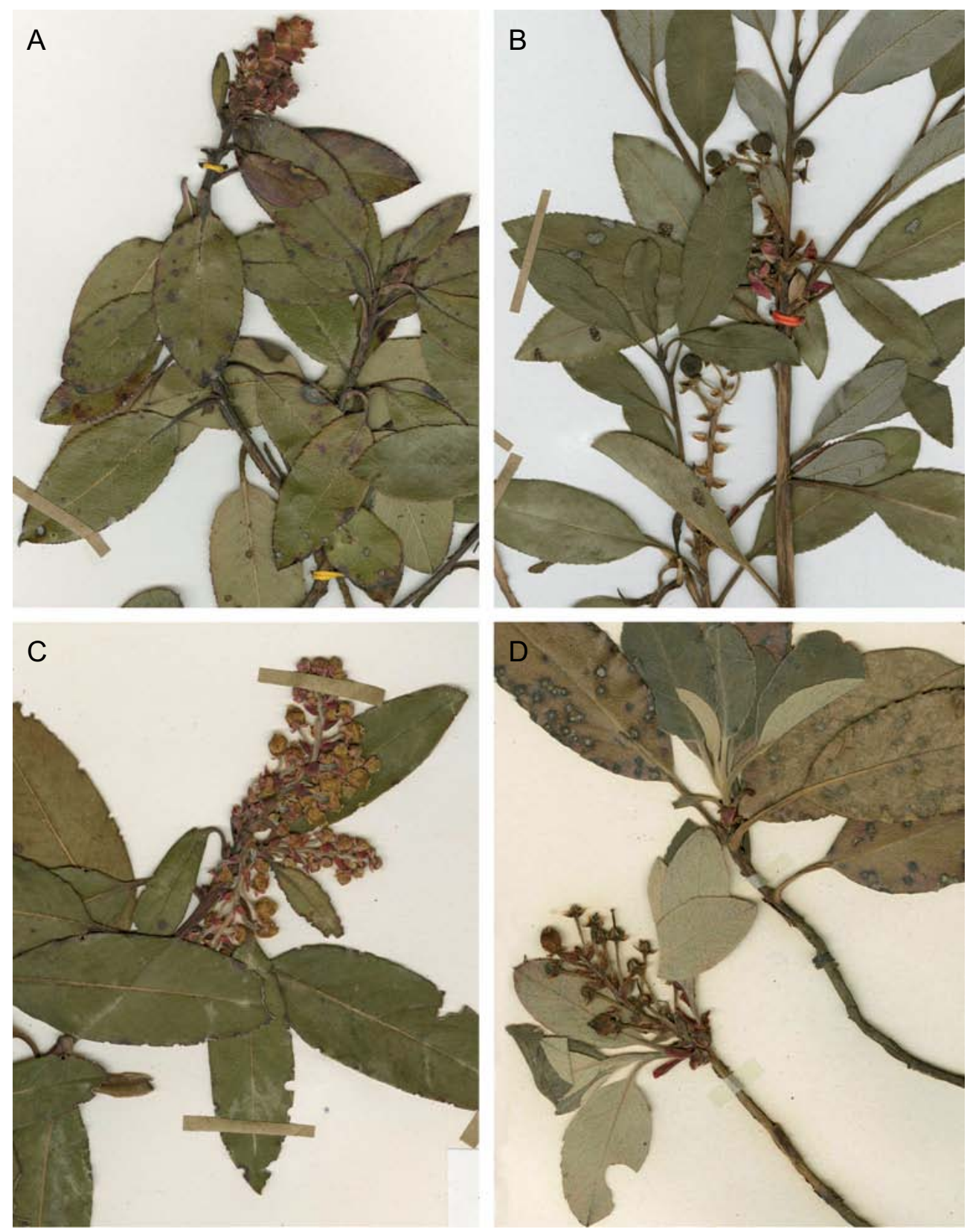

Fig. 6. Arbutus occidentalis, ramillas con flores o frutos: A. de localidad tipo en Jalisco (Iltis et al. 29390a); B. variante hojas membranáceas (González 5259); C. híbrido con A. arizonica (Cházaro et al. 4612); D. híbrido con A. bicolor (Palmer 195). 
Una explicación parcial del gran polimorfismo existente en estos grupos puede ser la ocurrencia de hibridación e introgresión entre varias especies de $\mathrm{Ar}$ butus. En Ericaceae es común que varios representantes del grupo se asocien entre sí y en algunos sitios llegan a encontrarse hasta seis taxa de esta familia (González-Villarreal, 1990), lo cual podría favorecer intercambio genético entre algunos de ellos. En Arbutus, los eventos de hibridación se observan particularmente en sitios con alta perturbación ambiental. Ejemplos de esto se presentan en González Elizondo y González-Elizondo (1992) y en González-Elizondo et al. (2012). La presencia de plantas con formas intermedias entre especies simplemente indica que la hibridación y la especiación están ocurriendo de manera continua (Mallet, 2005). El hecho de que tanto A. mollis como A. occidentalis ocasionalmente se reproducen de manera vegetativa favorece también la diversificación en estas especies. En Durango se encuentran poblaciones de A. occidentalis con tallos postrados que enraizan en los extremos y en Guanajuato ha sido observado lo mismo para A. mollis, de tal manera que otra fuente de polimorfismo en estas dos especies podría ser la reproducción asexual que favorece la formación de biotipos. Lo que hasta ahora se ha interpretado como individuos con caracteres intermedios que dificultan la delimitación y circunscripción entre $A$. mollis y A. occidentalis constituye ya sea: a) variantes morfológicas, b) híbridos o individuos con introgresión genética de otras especies, c) rebrotes a partir de tocones o formas enanas y depauperadas de otras especies, o d) formas arbustivas de otras especies. Estas últimas representan eventos aislados, pero su documentación es importante para entender las relaciones en el grupo.

En seguida se presentan las descripciones enmendadas de $A$. mollis y de $A$. occidentalis. No se registran híbridos entre estas dos especies, pero se documentan los siguientes híbridos con otras:

Arbutus mollis x A. tessellata P. D. Sørensen (de Guanajuato y Michoacán) Arbutus mollis x A. xalapensis (Querétaro) Arbutus occidentalis x A. arizonica (de Durango, Aguascalientes y Jalisco) Arbutus occidentalis $\mathrm{x}$ A. tessellata (de Jalisco)

Arbutus occidentalis x A. bicolor S. González, M. González et P. D. Sørensen (de Chihuahua y Durango) y

Arbutus occidentalis x A. aff. xalapensis (de Durango y Jalisco).

Arbutus mollis Kunth in H.B.K., Nov. gen. sp. (ed. quarto), 3(12): 280. (Nov) 1819 (como "1818”). Tipo: Mexico. Guanajuato: crescit propter Guanaxuato Mexicanorum, 
Sep 1893, A. Humboldt \& A. Bonpland s.n. aparentemente perdido (lectotipo, designado por Sørensen, 1995: descripción en Humboldt, Bonpland \& Kunth, Nov. gen. sp. 3. 1819). Arbutus occidentalis McVaugh \& Rosatti var. villosa McVaugh \& Rosatti. Contr. Univ. Michigan Herb. 11: 304. 1978. Tipo: Mexico. Mexico, Distr. Temascaltepec, between Cumbre and Cimientos, on cliff, 26.01 .1936 (fl), G.B. Hinton et al. 8847 (holotipo: MICH!; isotipos: C, GH!, K, LAM, MEXU!, NY!, US!).

Nombre común: madroño, madroño chaparro.

Arbusto de 0.2 a $1.2(-2) \mathrm{m}$ de alto, con rizomas a partir de un cormo; ramas erectas o postradas, a veces enraizando donde tocan el suelo; corteza exfoliante en laminillas, ramillas del año no o poco exfoliantes, corta y densamente pubescentes con tricomas lanosos blancos a ferrugíneos de 0.3 a $0.7 \mathrm{~mm}$ de largo, aplicados o casi, a veces también con tricomas glandulares de 0.1 a $0.3(-1.2) \mathrm{mm}$ de largo, las ramillas angulosas, de color café a púrpura bajo la pubescencia; peciolos 0.5 a $2(-2.5) \mathrm{cm}$ de largo, subrollizos a plano-convexos y algo acanalados adaxialmente, densamente pubescentes abaxial y adaxialmente, tricomas glandulares inconspicuos $(0.1$ a 0.3 $\mathrm{mm}$ ) o hasta de $1.2 \mathrm{~mm}$ de largo; hojas oblongas a ovadas u oblongo-lanceoladas, de 3.3 a $8.5 \mathrm{~cm}$ de largo y de 1.5 a $4 \mathrm{~cm}$ de ancho (hasta de $9 \mathrm{~cm}$ de largo y $5.1 \mathrm{~cm}$ de ancho en ramillas de rápido crecimiento), ápice agudo o corta y abruptamente acuminado, rara vez redondeado, base redondeada, truncada, ligeramente cordada $o$ cuneada, margen a veces con tinción púrpura, entero o aserrado con 0-7 dientes $/ \mathrm{cm}$ (en ramillas de rápido crecimiento pueden ser marcadamente aserradas), los dientes reducidos a un mucrón de 0.2 a $0.5 \mathrm{~mm}$, subcoriáceas a coriáceas, la nervadura media prominente en el envés, haz liso o reticulado, a veces ampuloso y diminutamente papiloso, finamente pubescente, opaco o algo lustroso, envés densamente tomentoso en hojas jóvenes, la pubescencia densa o espaciada en hojas maduras, los tricomas con frecuencia de dos tipos: unos cortos, crespos, lanosos y aplicados sobre toda la superficie, y otros filiformes y distribuidos a lo largo de las nervaduras principales, blanquecinos a ferrugíneos o cafés; inflorescencias terminales (a veces sobre ramillas) sésiles, laxas o densas, de 3 a $5(-6.5) \mathrm{cm}$ de largo y 1.5 a $4.8(-6.5) \mathrm{cm}$ de ancho, con un racimo primario y 0 a 6 racimos secundarios casi basales de 0.5 a 3.8(-4.5) $\mathrm{cm}$ de largo, los ejes y pedicelos canescente-tomentosos a ferrugíneo tomentosos y con tricomas glandulares de 0.1 a $1.2 \mathrm{~mm}$ de largo, brácteas tres en la base de los pedicelos, de color amarillento a rosado pálido o café rojizo, opacas, rara vez lustrosas, ocasionalmente glutinosas, la exterior de 2.1 a $7 \mathrm{~mm}$ de largo y 1.4 a $3.6 \mathrm{~mm}$ de ancho, ampliamente ovada a ovado-lanceolada, aguda, cóncava, densamente canes- 
cente exteriormente sobre toda la superficie o a lo largo de la parte media, a veces glandular pubescente, con ápice no escarioso o éste estrecho, densamente pubescente o rara vez glabro, las brácteas interiores de la mitad o menos de la mitad del tamaño de la exterior, opuestas, ovadas a lanceoladas, agudas, cóncavas, densamente pubescentes o pubérulas al menos sobre la parte media o a veces glabras; flores pediceladas, péndulas en la antesis, la corola de 4.7 a $6 \mathrm{~mm}$ de largo y de 3.3 a $4 \mathrm{~mm}$ de ancho, de color blanco a rosa o blanquecino con tono rojizo, lóbulos del cáliz triangulares o deltoides, de 1 a $2.3 \mathrm{~mm}$ de largo; base de los filamentos densamente pilosa, anteras de 1 a $1.5 \mathrm{~mm}$ de largo, apéndices 0.7 a $0.9 \mathrm{~mm}$; fruto rojo, con 2 a 4(8) semillas por lóculo, semillas de color pajizo, finamente lineoladas longitudinalmente.

Planta común a abundante en bosques de encino, pino o de pino-encino, Abies, bosque de Pinus y Alnus, y claros adyacentes (incluyendo "pastizal, entre el bosque de Abies religiosa, Quercus spp., Pinus rudis"), preferentemente en sustrato ígneo a excepción de algunas poblaciones en Querétaro y Oaxaca. Alt. 2500-3400 $\mathrm{m}$. Florece de octubre a abril y fructifica de junio a diciembre.

Se conoce del sur de Durango, sur de San Luis Potosí, Guanajuato, Querétaro, Hidalgo, Michoacán, Edo. de México, Guerrero y Oaxaca.

Durango: Pico La Grulla, predio Las Bayas, $23^{\circ} 27^{\prime} \mathrm{N}, 104^{\circ} 50^{\prime} \mathrm{W}$, mpio. Durango, S. González 4571 con A. García y S. Acevedo (CHAPA, CIIDIR, IEB); 1 km de La Escondida, mpio. El Mezquital, S. González y M. González 4895 (CIIDIR, IEB, MEXU, US); ibid., S. González y M. González 4897 (ANSM, CHAPA, CIIDIR, ENCB). San Luis Potosí: Mpio. Villa de Reyes, Las Ciénegas, Sierra de San Miguelito, 2790 m, M. F. Robert 1178 (CAS, ENCB, MICH). Guanajuato: Sierra al NE de León, E. Carranza, S. Zamudio y E. Pérez 4277 (IEB); presa Peralillo, mpio. Guanajuato, S. Zamudio y R. Murillo 6388 (IEB); presa Peralillo, El Puerto de Santa Rosa, mpio. Guanajuato, S. Zamudio y S. González 11356 (CIIDIR, IEB); ibid., S. Zamudio y S. González 11357 (IEB); ibid., S. Zamudio 15401 (IEB). Querétaro: al $\mathrm{S}$ del Cerro El Pingüical, municipio de Peñamiller, E. Carranza y S. Zamudio 3991

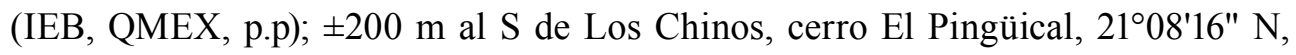
9941'39" W, municipio de Peñamiller, S. Zamudio y G. Aguilar 15106 (IEB). Michoacán: Estribaciones noroccidentales del cerro Patamban, mpio. Tangancícuaro, J. Rzedowski y R. McVaugh 659 (ENCB); lado NW cerro Patamban, mpio. Tangancícuaro, I. García 3700 (IEB); cumbre del cerro Viejo, mpio. Chilchota, J. A. Machuca 6224 (IBUG, IEB); ladera SE del cerro Grande, Sta. Cruz Tanaco, mpio. Cherán, $S$. Zamudio 5441 (ENCB, IEB, MEXU); cerro El Pilón, mpio. Nahuatzen, E. García 
y E. Pérez 3018 (CIIDIR, IEB); parte alta del cerro El Chivo, mpio. Tingambato, H. Díaz Barriga y E. Pérez 5967 (ENCB, IEB, MEXU); parte alta del cerro del Burro, cerca de Cuanajo, mpio. Pátzcuaro, H. Díaz Barriga 1013 (CHAPA, ENCB, IEB, MEXU); parte alta del cerro del Burro, mpio. Huiramba, J. Rzedowski 41935 (ENCB, IBUG, IEB); ladera oriental de la parte alta del cerro del Burro, mpio. Santa Clara del Cobre, E. Carranza 6431 (IEB); parte alta del cerro de Las Nieves, mpio. Huiramba, E. García L. y cols. 3511 (CIIDIR, IEB); cerro de Las Nieves, mpio. Huiramba, E. Carranza y S. Zamudio 4696 (IEB, MEXU); parte alta del cerro de Las Nieves, mpio. Huiramba, 3350 m, H. Díaz Barriga y E. García 7008 (IEB); cerro El Burro, mpio. Santa Clara del Cobre, E. Pérez 626 (IEB); ibid., E. Pérez 728 (IEB); cerro Tancítaro, $27 \mathrm{~km}$ al W de Uruapan en línea recta, aprox. $1 \mathrm{~km}$ al NW de San Nicolás, $19^{\circ} 25^{\prime} \mathrm{N}, 102^{\circ} 14^{\prime} \mathrm{W}$, mpio. de Tancítaro, I. García Ruiz 4048 con J. A. Machuca y M. Cházaro (IEB); cerro Tancítaro, $27 \mathrm{~km}$ al W de Uruapan en línea recta, aprox. $2 \mathrm{~km}$ al $\mathrm{N}$ de San Nicolás, $19^{\circ} 25^{\prime} \mathrm{N}, 102^{\circ} 17^{\prime} \mathrm{W}$, mpio. de Tancítaro, I. García Ruiz 4092 con J. A. Machuca y M. Cházaro (IEB, MEXU); aprox. $1 \mathrm{~km}$ al W del cerro La Cruz, 19²3'55" N, 102²0'40" W, I. García Ruiz 4662 con J. A. Machuca y $R$. Acevedo (IEB); pedregal de Capacuaro, municipio de Uruapan, $H$. Díaz-Barriga 6732 (IEB); parte alta del cerro del Águila, mpio. Paracho, E. García y cols. 3141 (IEB, MEXU). Hidalgo: Las Navajas, $3 \mathrm{~km}$ al NE de Nopalillo, mpio. Epazoyucan, M. Medina y M. Barrios 3697 (ENCB, IEB). Edo. de México: Distr. Temascaltepec, between Cumbre and Cimientos, G.B. Hinton et al. 8847 (tipo de A. occidentalis var. villosa: MICH!; C, GH!, K, LAM, MEXU!, NY!, US!); Distr. Sultepec, Almoloya, G.B. Hinton et al. 15422 (US). Guerrero: vertiente SW del cerro Teotepec, mpio. Tlacotepec, aprox. $17^{\circ} 29^{\prime} \mathrm{N}, 100^{\circ} 12^{\prime} \mathrm{W}$, J. Rzedowski y R. McVaugh 210 (ENCB, IEB); Mina, G.B. Hinton et al. 14215 (US). Oaxaca: Comunidad de San Pablo Macuiltianguis, mpio. San Pablo Macuiltianguis, E. Guizar N. 801 (IEB); cerro de Humo in Sierra de Juárez, Alexander 829 (MICH, según McVaugh y Rosatti, 1978); ibid., R. Gereau 1972 (MEXU); brecha al cerro Pelado, Capulalpam de Méndez, Sierra Norte, 96²3'43" N, 17¹9’59" W, G. Juárez García 2981 (MEXU). México (país): sin localidad, C. Ehrenberg 926 (MEXU); Herbario F. Altamirano ex Museo Botanico, Berolinense (C. Ehrenberg) 926 (MEXU).

Arbutus mollis representa un complejo con diversas variantes morfológicas (Fig. 2 A-D; 3 A-C) y amplia distribución (Fig. 7), principalmente del Eje Neovolcánico pero con representantes en la Sierra Madre Occidental (Durango), Sierra Madre del Sur (Guerrero) y Sierra Madre Oriental (Hidalgo). Son arbustos de 0.2 a 1.2(-2) m de alto, ya sea con rizoma alargado o a partir de un grueso cormo. Dos registros de 


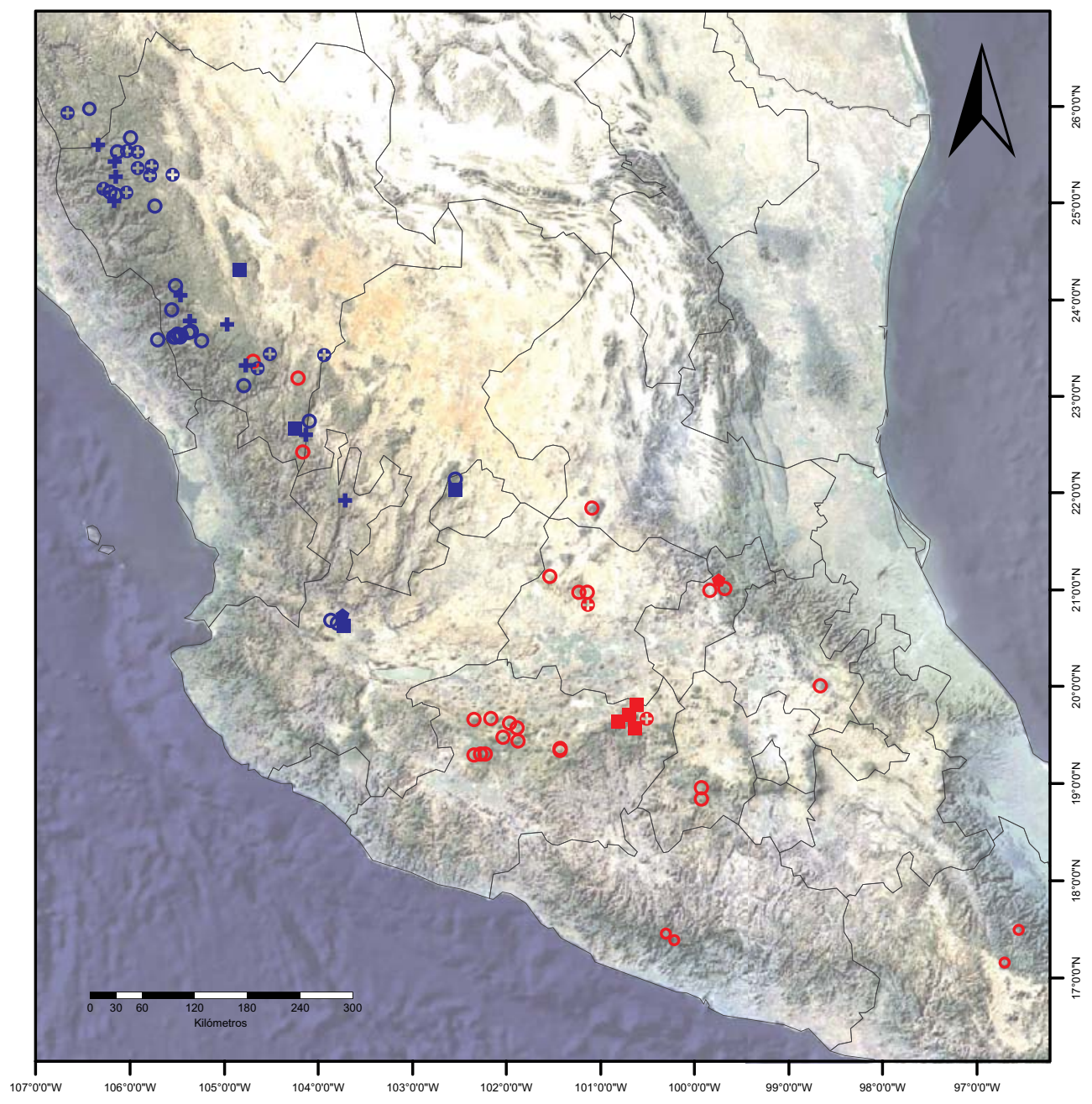

\section{Simbología}
- A. mollis
o A. occidentalis
- A. mollis f. glandular
$\oplus$ A. mollis $\times$ A. tessellata
A. mollis $\times$ A. xalapensis
- A. occidentalis $\times$ A. arizonica
$\oplus$ A. occidentalis $\times$ A. bicolor
A. occidentalis $\times$ A. tessellata
+ A. occidentalis $\times$ Arbutus $\mathrm{sp}$.

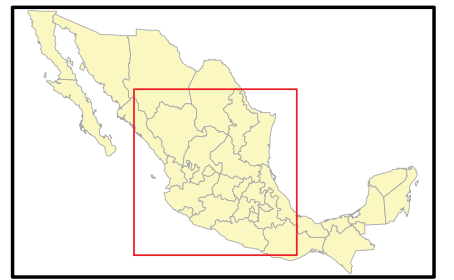

Fig. 7. Distribución geográfica conocida de Arbutus mollis, A. occidentalis e híbridos con otras especies de Arbutus. 
arbolitos, uno de $3 \mathrm{~m}$ (Díaz-Barriga 6732, IEB) y otro hasta de $6 \mathrm{~m}$ (Carranza 391, IEB) representan probablemente plantas con introgresión genética de un Arbutus arbóreo. Las hojas de A. mollis por lo general son oblongas, ovadas o angostamente elípticas pero existe gran diversificación en su forma, en el tipo de pubescencia, el grado de glandulosidad y la forma e indumento de las brácteas de la inflorescencia, entre otros rasgos, de tal manera que algunas de las variantes pudieran ameritar reconocimiento taxonómico. Las plantas de Guanajuato (incluyendo las de la localidad tipo de A. mollis) tienen hojas ampliamente oblongas $(3.3-6.3 \times 2.4-3.7 \mathrm{~cm})$, redondeadas a truncadas en la base, espaciadamente lanoso-pubescentes en el envés con hojas jóvenes densamente ferrugíneo-pubescentes, más o menos lisas y opacas en el haz y se desarrollan entre 2500 y $2600 \mathrm{~m}$ de altitud, más abajo que el resto de las poblaciones del grupo, en bosque de encino (por ejemplo: E. Carranza 4277 IEB y $S$. Zamudio y R. Murillo 6388 IEB). Las de Michoacán, Hidalgo, Estado de México y Guerrero se desarrollan a mayores elevaciones y tienen hojas densamente lanoso-pubescentes en el envés. En las de Michoacán las hojas son relativamente más largas, elípticas a oblongo-lanceoladas y con frecuencia cuneadas en la base, algunas lanoso-ferrugíneas y otras lanoso-blanquecinas en el envés. Las del Estado de México, Guerrero y Oaxaca tienen el haz algo lustroso y ampuloso debido a la impresión de las ramillas.

La variante glandular de A. mollis.

La pubescencia de las ramillas y peciolos de A. mollis varía de casi eglandular (como en las plantas de la localidad tipo) a con tricomas glandulares inconspicuos (de 0.1- 0.3 mm), o con abundantes tricomas glandulares de (0.1-)0.4-1.2 mm. La variante con pubescencia glandular densa y perceptible a simple vista, hasta de 1.2 $\mathrm{mm}$ en las ramillas del año, pecíolos e inflorescencias (Fig. $3 \mathrm{C}, 5 \mathrm{~F}$ ) se caracteriza además por presentar hojas elípticas a estrechamente oblongas con margen entero o espaciadamente aserrado (dientes $0-4 / \mathrm{cm}$ ), a veces con tricomas glandulares espaciados hasta de $0.7 \mathrm{~mm}$ long y envés densamente ferrugíneo-pubescente, la pubescencia cubriendo toda o casi toda la superficie. Son arbustos de 0.3-0.6 m. Estas plantas restringen su distribución al noreste de Michoacán (Fig. 7), donde se concentran particularmente en áreas rocosas de laderas y cañadas con bosque de pino, de pino y Abies o de Abies con algunos pinos, entre (2720-)2870 y $2950 \mathrm{~m}$. Se han colectado en flor de diciembre a marzo y presentan fruto de febrero a diciembre. Aunque se ha discutido mucho si la presencia de tricomas glandulares está ligada a aspectos ambientales, en este caso no parece haber ninguna correlación entre su presencia y el ambiente. 
Michoacán: Los Azufres, mpio. Zinapécuaro, D. Fuentes s.n., 1957 (ENCB); Laguna Los Azufres, mpio. Zinapécuaro, L. M. González Villarreal 3247 (IBUG2); Laguna Los Azufres, mpio. Zinapécuaro, H. Díaz Barriga y S. Zamudio 2688 (ENCB, IEB, MEXU); Laguna Los Azufres, mpio. Zinapécuaro, S. Zamudio 3919 (ENCB, IBUG, IEB); presa Llano Grande, Los Azufres, mpio. Zinapécuaro, S. Zamudio y H. Díaz Barriga 5174 (IEB); $300 \mathrm{~m}$ aprox. al S del Campamento "Agua Fría", mpio. Ciudad Hidalgo, en ladera rocosa, E. Carranza 391 (IEB); Los Azufres, zona geotérmica, mpio. Ciudad Hidalgo, J. S. Martínez 2003 (ENCB, IBUG, IEB); cerro El Chino, Los Azufres, mpio. Zinapécuaro, S. Zamudio 5997 (IEB, MEXU).

Tres colectas de Durango con pubescencia lanosa blanquecina en el envés se reconocen tentativamente como A. mollis, aunque se considera también la posibilidad de que representen híbridos entre Arbutus occidentalis y A. xalapensis ya que, además de su disyunción geográfica con respecto a la zona donde se concentra $A$. mollis, presentan algunas diferencias morfológicas: la colecta con flores (S. González 4993) las tiene de color amarillo pálido como en A. xalapensis, otra (S. González 4571) (Fig. 1 D, 3 D) tiene brácteas exteriormente glabras o ligeramente pubescentes sobre la parte media, lustrosas y rojizo oscuras como en $A$. occidentalis; algunas presentan margen de las hojas ligeramente ondulado, común en algunos híbridos. Sin embargo, debido a que su apariencia es muy similar a la variante de $A$. mollis del noroeste de Michoacán con hojas elípticas, dientes espaciados y pubescencia blanquecina (por ejemplo, a las colectas de García 3700 y 4092), son tratadas como $A$. mollis. Las plantas de San Luis Potosí (Robert 1178 CAS) se incluyen bajo A. mollis también de manera tentativa.

Otras variantes que difieren en uno o varios rasgos de las características comunes de A. mollis son las siguientes: a) Plantas con 2-3(-8) semillas por lóculo ( $\mathrm{S}$. Zamudio y R. Murillo 6388). A este respecto Sørensen (1995: 199) menciona que Palser (1954) reportó hasta 10 óvulos/lóculo, pero que él solamente ha observado de 1 (en A. occidentalis) a 4-5 semillas (en A. xalapensis), añadiendo que en $A$. occidentalis el promedio es de dos. La muestra de Zamudio y R. Murillo 6388 se cataloga como parte de $A$. mollis por tener hábito arbustivo bajo y hojas pequeñas densamente lanoso pubescentes en el envés. b) Plantas hasta de $2 \mathrm{~m}$ de alto, con un apéndice escarioso de 0.3-0.4 x 0.1-0.2 mm entre los dos poros de las anteras. Solo se han registrado del Cerro del Burro, Michoacán (Díaz Barriga 1013 IEB). c) Plantas con el envés de las hojas con densa pubescencia canescente afectada por un hongo (E. Carranza 6431 IEB), a diferencia otras de la misma zona (Cerro del Burro) que tienen pubescencia ferrugínea. d) Una sola colecta (E. Carranza 391 IEB) registra hábito arbóreo, hasta de $6 \mathrm{~m}$ de alto, probablemente por introgresión de otra especie de tal forma biológica. 


\section{Híbridos}

Arbutus mollis $\mathbf{x}$ A. tessellata: Individuos aislados, escasos, presentan características intermedias entre $A$. mollis y $A$. tessellata, especie arbórea abundante en los dos sitios donde se han registrado los híbridos. Son arbustos hasta de $2 \mathrm{~m}$ de alto, con corteza exfoliante en placas pequeñas y alargadas, de color café rojizo, de tal manera que la corteza interior no queda lisa sino rugosa y con tricomas glandulares de 0.5 a $1.8 \mathrm{~mm}$ de largo. Con A. tessellata comparten la pubescencia glandular, la forma y tamaño de las hojas con margen uniformemente aserrado y consistencia menos coriácea que en $A$. mollis y en algunos casos la corteza teselada en la base de la planta. De $A$. mollis heredaron el hábito arbustivo, la pubescencia lanosa en el envés y las flores blancas con tinte rosa (las de $A$. tessellata son blanco verdosas).

Guanajuato: presa Peralillo, El Puerto de Santa Rosa, mpio. Guanajuato, $S$. Zamudio y S. González 11358 (IEB). Michoacán: presa Llano Grande, Los Azufres, mpio. Zinapécuaro, S. Zamudio y H. Díaz Barriga 5154 (ENCB, IEB); ibid., S. Zamudio y H. Díaz Barriga 5156 (IEB).

Arbutus mollis $\mathbf{x}$ A. xalapensis: Arbutus mollis y A. xalapensis son simpátricas en el norte de Querétaro, donde se presenta un enjambre híbrido entre ambas en el que $A$. mollis parece estar desapareciendo, absorbido por la segunda. Esta población mixta está formada por arbustos de 0.4-2.5 m de alto, con frecuencia algo postrados, con ramillas de menos de $3 \mathrm{~mm}$ de ancho; peciolos $0.6-2 \mathrm{~cm}$ de largo con tricomas simples y a veces también glandulares, hojas relativamente pequeñas (4.3$5.8 \times 2.3-3.2 \mathrm{~cm}$ ) o grandes en brotes de rápido crecimiento, lustrosas u opacas en el haz, el envés densamente flocoso pubescente en hojas jóvenes, particularmente a lo largo de la nervadura central, luego glabrescente, margen aserrado o entero; inflorescencias densas, brácteas 2.5-4 $\mathrm{mm}$ de largo, 1.9-2.5 $\mathrm{mm}$ de ancho, densamente pubescentes; flores blanco-rosadas o blancas con tonos rojizos. En bosque de Pinus rudis y en matorral esclerófilo de Quercus, Arctostaphylos y Garrya. A1. 2900-3100 m. En floración de abril a junio, frutos de mayo a septiembre.

Querétaro: cerro El Pingüical, municipio de Peñamiller, S. Zamudio 3650 (IEB); parte alta del cerro El Pingüical, $2 \mathrm{~km}$ al $\mathrm{W}$ de la antena, municipio de Peñamiller, S. Zamudio y E. Carranza 6875 (IEB, QMEX); al S del cerro El Pingüical, municipio de Peñamiller, E. Carranza y S. Zamudio 3992 (IEB, QMEX); ladera S del cerro El Pingüical, municipio de Peñamiller, 8.06.2001, S. Zamudio y S. González 11726 (IEB, QMEX); alrededores del cerro de La Calentura, municipio de Pinal de Amoles, J. Rzedowski 48232 (CIIDIR, IEB); cerro de La Calentura, al N de El Madroño, municipio de Pinal de Amoles, E. Carranza 2547 (IEB); cerro La Calen- 
tura, municipio de Pinal de Amoles, S. Zamudio 3638 (IEB); cerro de La Antena, al WSW de San Gaspar, municipio de Pinal de Amoles, E. Carranza 2076 (IEB).

Cabe señalar que algunas de las variantes de $A$. mollis con hojas elípticas densamente pubescentes presentan una semejanza superficial con especies de $\mathrm{Co}$ marostaphylis, por el radio longitud-ancho de las hojas y por el tipo de pubescencia, particularmente en los casos de plantas con peciolos cortos (peciolos $0.5-1.5 \mathrm{~cm}$ con láminas 5.5-8.3 cm), por ejemplo las colectas de E. García y E. Pérez 3018, E. García et al. 3141 y E. Pérez 626. A su vez, plantas de Comarostaphylis mucronata con hojas ovadas de base redondeada se asemejan superficialmente a Arbutus mollis. Ambos géneros pueden ser claramente separados mediante la disección de los frutos: en Arbutus la separación entre lóculos en frutos maduros es fina y algo translúcida, usualmente el pericarpio es también fino y la remoción del exocarpio revela la presencia de 2 a 4(8) semillas por lóculo, muy raramente solo una, y los frutos usualmente son frágiles y se aplanan fácilmente al ser prensados. En Comarostaphylis el mesocarpio es óseo y su disección muy difícil, los carpelos están unidos y siempre hay una semilla por lóculo. La colecta de E. Pérez 626 presenta caracteres intermedios entre ambos géneros: una gran similitud con Comarostaphylis por los pecíolos cortos, láminas angostas marcadamente cuneadas en la base y una sola semilla por lóculo, pero con separación entre lóculos muy frágil, como en Arbutus, por lo que cabe la posibilidad de que represente un híbrido intergenérico.

Arbutus occidentalis McVaugh \& Rosatti, Contr. Univ. Michigan Herb. 11: 303. 1978. Arbutus occidentalis McVaugh \& Rosatti var. occidentalis. Tipo. México. Jalisco: Autlán, Sierra de Manantlán, along lumber roads east of the summit between El Chante and Cuzalapa, $19^{\circ} 35^{\prime} \mathrm{N}, 104^{\circ} 8^{\prime}-15^{\prime} \mathrm{W}$, summits of cliffs in pine-forest, 2750 m, 20-21 Mar 1965 (fl), McVaugh 23129 (holotipo: MICH).

Madroñito, madroño, madroño chaparro.

Arbusto de (0.1-)0.2 a 0.5(-0.8) $\mathrm{m}$ de alto, cubriendo áreas de 1 a $3 \mathrm{~m}$ de diámetro, perennifolio, ramas postradas o suberectas, a veces enraizando donde tocan el suelo; corteza exfoliante en segmentos rectangulares o alargados, dejando al descubierto la corteza interior de color café a rojizo; ramillas del año pubescentes o puberulentas, con frecuencia con franjas glabras, exfoliantes o poco exfoliantes, lustrosas u opacas, de color café rojizo; ramillas del segundo año 1.5-3 $\mathrm{mm}$ de diámetro, exfoliantes en laminillas de $1-4 \mathrm{~mm}$ de largo; peciolo de 0.4 a $1.7 \mathrm{~cm}$ de 
largo, plano-convexo, acanalado sobre el lado adaxial, con frecuencia con tonos rojizos, con pubescencia solo sobre el lado adaxial, glabro o rara vez puberulento abaxialmente; hojas ovadas, elípticas o estrechamente oblongas, de 2.5 a $5.4 \mathrm{~cm}$ de largo y de 1 a 2.3(-2.6) $\mathrm{cm}$ de ancho, el ápice agudo a cortamente acuminado, la base ampliamente cuneada a redondeada, simétrica a ligeramente asimétrica, margen usualmente teñido de púrpura, fina y uniformemente aserrado con 5-13 dientes/ $\mathrm{cm}$, a veces doblemente aserrado, los dientes terminan en un mucrón blanco de 0.2 a $0.7 \mathrm{~mm}$, coriáceas a subcoriáceas, haz de color verde obscuro, lustroso, glabro o pubescente sobre la nervadura central, rara vez ligeramente pubescente sobre nervaduras laterales, reticulado debido a las venillas secundarias prominentes, envés de color verde pálido, verde amarillento o glauco, opaco, glabro aún en hojas jóvenes, rara vez puberulento o con indumento con apariencia de diminutos cristales; inflorescencias terminales cortas, compactas o laxas, de $1 \mathrm{a} 5.5 \mathrm{~cm}$ de ancho, a veces con solo 2 a 8 frutos, con un racimo primario y 0 a 4 racimos secundarios casi basales de $1 \mathrm{a} 5 \mathrm{~cm}$ de largo, ejes y pedicelos pubescentes con tricomas simples, a veces también con tricomas glandulares inconspicuos, los tricomas no glandulares torcidos en forma de tirabuzón pero ondulados a rectos en su apariencia general o a veces crespos; pedicelos de $0.5 \mathrm{a} 1 \mathrm{~cm}$ de largo, hasta de $1.6 \mathrm{~cm}$ de largo en fruto, pubescentes o distalmente glabros; bráctea exterior de 2.2 a $6 \mathrm{~mm}$ de largo y 1.2 a $4.5 \mathrm{~mm}$ de ancho, de color rosa a café rojizo oscuro, gruesa, lustrosa, con frecuencia glutinosa, glabra o puberulenta exteriormente excepto por el margen ciliado a ciliado-glandular, el lado interior (adaxial) glabro o pubescente sobre la parte media, con ápice escarioso estrecho a amplio o ausente, las dos brácteas interiores de la mitad o menos de la mitad del tamaño de la exterior; flores pediceladas, péndulas en la antesis; lóbulos del cáliz triangulares, de 1.3 a 2.3(-3.2) $\mathrm{mm}$ de largo, reflejos a la madurez del fruto, con ápice agudo u obtuso, ciliado; corola de 4 a $6 \mathrm{~mm}$ de largo, de color rosa o blanco rosado, rara vez blanco, glabra o espaciadamente pubescente exteriormente, espaciadamente pubescente interiormente, los lóbulos con márgenes auriculados imbricados, reflejos al madurar la flor; anteras de 1 a $1.2 \mathrm{~mm}$ de largo, dehiscentes por poros de un tercio del largo de la antera, con apéndices delgados de 0.5-0.6 mm de largo, base de los filamentos densamente pilosa; fruto hasta de $0.9 \mathrm{~cm}$ de largo y de 0.7 a $0.9 \mathrm{~cm}$ de diámetro, de color rojo intenso o rojo obscuro; semillas 1-2(-3) por lóculo, de color pajizo, finamente lineoladas longitudinalmente (Fig. 6 A, $3 \mathrm{D}, 4 \mathrm{~B}, 5 \mathrm{~A})$.

En ocasiones, en $A$. occidentalis las inflorescencias son muy compactas, con ramillas muy reducidas y lo que aparentan ser brácteas florales son en realidad brác- 
teas de las ramillas de la inflorescencia, las cuales (en este caso de 5.1-7 x 4.8-6.3 $\mathrm{mm}$ ) aparecen cubriendo solo una flor con sus respectivas brácteas del pedicelo (ej. en Iltis et al. 29390a; González V. y Pérez de la R. 2498; Santana y Cuevas 3423).

Plantas con introgresión genética de otras especies de Arbutus pueden presentar peciolos puberulentos abaxialmente y hojas ligeramente más grandes que en A. occidentalis (por ejemplo, las colectas de Tenorio et al. 6216 y de Cházaro y Rodríguez 5118). Otras tienen peciolos con diminutos tricomas glandulares y envés de hojas jóvenes puberulento abaxialmente (ej. González 4842a, Fig. 4 B, 5 C). Por sus vistosas hojas lustrosas y el hábito arbustivo que cubre el suelo, la especie tiene buen potencial como planta ornamental.

Arbutus occidentalis se desarrolla en bosques húmedos de Pinus, Quercus o Abies, bosques de Pinus, Quercus y Cupressus, bosques de Quercus, Pinus у Juniperus, así como en bosque mesófilo de montaña con Abies, Quercus, Cupressus, Arbutus y Pinus. Muestra preferencia por áreas con afloramiento rocoso en cimas, collados y laderas. Alt. (2050-)2400 a $3200 \mathrm{~m}$.

Se conoce del sur de Chihuahua, oriente de Sinaloa, Durango, Jalisco y Aguascalientes (Fig. 7). Florece y fructifica de abril a noviembre.

Chihuahua: South-western Chihuahua, E. Palmer V-V(US). Sinaloa: El Carrizo, Sindicatura Pánuco, mpio. Concordia, J. González O. 314 (MEXU). Durango: Altos de Yesqueros, camino de El Huacal a Quebrada Honda, 2534' N, 106 $24^{\prime}$ ' W, mpio. Tepehuanes, M. González 2463 (CIIDIR); El Yaqui, al W, por la carretera a Topia, 2502'59" N, 10559'16" W, mpio. Santiago Papasquiaro, S. González 6268

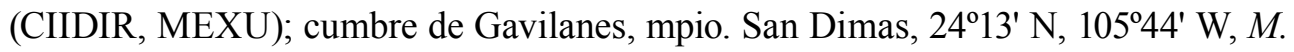
A. Márquez s.n. (CIIDIR, MEXU); $52 \mathrm{~km}$ del entronque de la brecha a San Miguel de Cruces, con la carr. Durango - Mazatlán, mpio. San Dimas (con ligera pubescencia ferrugínea, introgresión de A.xalapensis), P. Tenorio L. 886 C. Romero de T. (CIIDIR, MEXU); Jacales, $44 \mathrm{~km}$ al SW de San Miguel de Cruces, brecha a Tayoltita, mpio. San Dimas, P. Tenorio et al. 6216 (CIIDIR, MEXU); Sierra de Chavarría, mpio. Pueblo Nuevo, J. González O. 4075 (US); Espinazo del Diablo, pasando Puerto de Buenos Aires, rumbo a Mazatlán, mpio. Pueblo Nuevo, M. Cházaro y A. Rodríguez 5118 (IEB); km 131 carretera Durango - Mazatlán, mpio. Pueblo Nuevo, S. González y M. González 4839 (CIIDIR, ENCB, IEB, MEXU); km 153 carretera Durango - Mazatlán, cerca del Puerto de Buenos Aires, mpio. Pueblo Nuevo, S. González y M. González 4842a (CIIDIR, NY); hwy 40, 43 km from Sinaloa - Durango border, km 154.5, Puerto de Buenos Aires, F. C. Boutin \& D. R. Hunt 3912 (MEXU, US); Puerto 
de Buenos Aires, F. C. Boutin \& D. R. Hunt 3885 (MEXU); Mexiquillo, aprox. 3 km

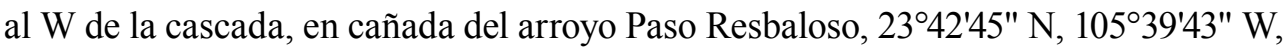
S. González 6811 con P. M. Peterson y G. Tena (CIIDIR, IEB); Mexiquillo, al W de la cascada, orilla N de la cañada del arroyo La Quebrada, $23^{\circ} 42^{\prime} 40^{\prime \prime} \mathrm{N}, 105^{\circ} 39^{\prime} 32^{\prime \prime} \mathrm{W}, S$. González 6817 con P. M. Peterson y G. Tena (ANSM, CIIDIR, ENCB, IEB, MEXU, US); Mexiquillo, cerca de La Ciudad, mpio. Pueblo Nuevo, S. Zamudio 13221 (IEB); $20 \mathrm{~km}$ northeast of La Ciudad on Mexican highway 40, municipio de Pueblo Nuevo, D. E. Breedlove 45850, F. Almeda (MEXU); near El Salto, F. T. Sesock s.n. (US); La Peña, al SE, por el camino a Pueblo Nuevo, S. González 6824 con P. M. Peterson y G. Tena (CIIDIR); Mexiquillo, $100 \mathrm{~m}$ al N de la cascada, mpio. Pueblo Nuevo, 234' $48^{\prime \prime}$ N, 105²0'22" W, S. González et al. 6975 (CIIDIR, IEB); Sierra Madre Occidental, along dirt road $24 \mathrm{~km}$ south of El Salto toward Pueblo Nuevo, at junction with road

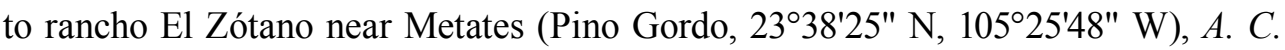
Sanders 22660, M. Egger, F. M. Roberts, G. Ferguson, S. Eliason (MEXU); Sierra del Nayar, Predio Molinillos (Toño Mancinas), entrada, 233' $16^{\prime \prime}$ N, $105^{\circ} 03^{\prime} 09^{\prime \prime}$ W, S. González foto (CIIDIR); Arroyo Santa Bárbara, al SW de El Salto, mpio. Pueblo Nuevo, 2336' N, 105²5' W, 27 Jun 1992, S. González 5259 (CIIDIR, IEB); Arroyo Santa Bárbara, al SW de El Salto, mpio. Pueblo Nuevo, 2336' N, $105^{\circ} 25^{\prime} \mathrm{W}$ (ramillas lisas, hojas finamente pubescentes), S. González 5257 (CIIDIR, IEB). Aguascalientes: $14 \mathrm{~km}$ al SW de La Congoja, Sierra Fría, mpio. San José de Gracia, 2111'08" N, 102³8'25" W, S. González 6228 (CIIDIR); 12 km al SW de La Congoja, Sierra Fría, mpio. San José de Gracia, L. M. González V., J. A. Pérez de la R. y R. Ramírez 2780 (CHAPA, ENCB-dos ejemplares); $10 \mathrm{~km}$ al SW de La Congoja, Sierra Fría, mpio. San José de Gracia, 2211'40" N, 102³8'08" W, S. González 6233 (CIIDIR, HUAA, IEB, MEXU). Jalisco: base $\mathrm{W}$ de La Tetilla del Volcán de Tequila, mpio. Tequila, $R$. Soltero O. 264 (IBUG); Volcán de Tequila, camino estación de microondas - La Teti1la, L. M. González V., R. Ramírez Delgadillo y J. A. Pérez de la Rosa 3535 (IBUG); ibid., L. M. González V., R. Ramírez Delgadillo y J. A. Pérez de la Rosa 3537 (IBUG); cerro de Tequila, cerca de La Tetilla, mpio. Tequila, C. L. Díaz L. 16272 (ENCB); Sierra de Manantlán, R. McVaugh 23129 (MICH!, holotipo); near El Guisar along logging road from El Chante in the Sierra de Manantlán, mpio. Autlán de Navarro, D. E. Breedlove y F. Almeda 45688 (MEXU); top of sharp crest of the Sierra de Manantlán Oriental just E of Cerro Las Capillas, along road from C. La Cumbre to Los Jardines, $19 \mathrm{~km}$ due SSE of El Chante, 19³3'15" N, 10409' W, H. H. Iltis y R. Guzmán 3203 (CHAPA, ENCB; IBUG-2 fotocopias, MEXU); ibid., P. D. Sørensen \& P. Matekaitis 7910A, H. H. Iltis, G. E. Schatz (MEXU); cerro Capulín, Reserva de la Biosfera Sierra de Manantlán, $19^{\circ} 33^{\prime} \mathrm{N}, 104^{\circ} 09^{\prime} \mathrm{W}$, H. H. Iltis et al. 29390 (topotipo, IEB); 21-22 
km al NW de Minatitlán, Capillas, cerro de las Capillas, mpio. Cuautitlán, 19³3'26" N, 104'09'30" W, F. J. Santana y R. Cuevas 3423 (ENCB, IBUG); cerro de las Capillas, 23-24 km al NEE de Cuautitlán, 7-8 km al SE de Rincón de Manantlán, mpio. Cuautitlán, 19³3'19" N, 10409'13" W, L. Guzmán y L. Hernández 1039 (MEXU); Las Capillas, al E de Autlán, en la Sierra de Manantlán, R. Guzmán 900 (ENCB); Capillas, mpio. Cuautitlán, R. Cuevas 1607 (IBUG, IEB); Capillas, mpio. Cuautitlán, R. Cuevas y M. Rosales 2003 (IBUG); Las Capillas, mpio. Cuautitlán, L. M. González V. y J. A. Pérez de la Rosa 2498 (CHAPA, ENCB, IBUG-2, IEB); Las Capillas, Sierra de Manantlán, mpio. Cuautitlán, L. M. V. de Puga et al. 11980 (IBUG-2, MEXU).

Una variante con hojas membranáceas a subcoriáceas, marcadamente glaucas en el envés, donde destaca la reticulación oscura de las nervaduras ( $S$. González 5259) (Fig. 6 B) se conoce de la cañada de Santa Bárbara, en Durango, donde es escasa en sotobosque de Pseudotsuga menziesii, Picea chihuahuana, Quercus spp. y Abies durangensis. Otras plantas del mismo sitio presentan las características generales de $A$. occidentalis pero difieren por tener ramillas del segundo año gruesas y lisas, y hojas e inflorescencias ligeramente pubescentes (S. González 5257), probablemente como resultado de introgresión genética de A. xalapensis.

\section{Híbridos}

Arbutus occidentalis x A. arizonica. En Durango, Aguascalientes y Jalisco, entre los 2700 y $2920 \mathrm{~m}$ de altitud, se desarrollan plantas que presentan una fuerte similitud morfológica con A. arizonica (A. Gray) Sarg. y con A. occidentalis, las cuales parecen representar híbridos entre ambas especies. Poblaciones de A. occidentalis de Jalisco (Volcán de Tequila) y Aguascalientes (Sierra Fría, mpio. San José de Gracia) se mezclan con arbustos erectos de 1.5 a $2 \mathrm{~m}$ de alto, que presentan características de individuos juveniles de $A$. arizonica en los caracteres vegetativos, pero que tienen inflorescencias reducidas, como en $A$. occidentalis. El típico A. arizonica presenta inflorescencias hasta de 48 frutos, compuestas de racimos hasta de 15 frutos (o más) y láminas agrupadas al final de las ramillas. Arbutus arizonica se desarrolla ocasionalmente en forma de "arbustos achaparrados" hasta de $2 \mathrm{~m}$ de alto en el Volcán de Tequila, Jal. y en la Sierra Fría, Ags., en sitios donde también crece $A$. occidentalis. Ejemplos de A. arizonica arbustivos debido a la elevación y al disturbio son las colectas de González Villarreal 2720 y de Cházaro y Patiño 7156. En Jalisco estos arbustos llegan a formar matorrales. Una población de Aguascalientes, ejemplar citado como paratipo de $A$. occidentalis, coincide en la altitud $(2700 \mathrm{~m})$ pero se parece a $A$. arizonica por tener hojas hasta de $6.1 \times 2.5 \mathrm{~cm}$, con peciolos de $1.8 \mathrm{~cm}$. 
Plantas con caracteres intermedios entre ambas especies (Fig. $6 \mathrm{C}$ ) son arbustos o arbolitos de 0.4-2 $\mathrm{m}$, con hojas de 4 a $9 \mathrm{~cm}$ de largo y 2 a $4 \mathrm{~cm}$ de ancho, glaucas o amarillentas en el envés, con frecuencia subcoriáceas a coriáceas, enteras o con dientes espaciados, peciolos hasta de $3.2 \mathrm{~cm}$ de largo, glabros excepto por muy escasos tricomas glandulares inconspicuos (ramillas del año, hojas y peciolos con apariencia de $A$. arizonica) o pubescentes adaxialmente (como en $A$. occidentalis), e inflorescencias densas o laxas, hasta de $5.5 \mathrm{~cm}$ de ancho, 3-4 racimos por inflorescencia, el terminal de 4 a $4.4 \mathrm{~cm}$ de largo y 1.8 a $2 \mathrm{~cm}$ de ancho, con ejes y pedicelos densamente pubescentes, brácteas y sépalos glabros o pubescentes solo en el ápice, brácteas de 3 a $3.5 \mathrm{~mm}$ de largo y de 2.5 a $3 \mathrm{~mm}$ de ancho; flores blancas, amarillentas o amarillento-verdosas. Raramente árboles (ej. Vázquez Prado 87) pero con hojas coriáceas marcadamente más pálidas en el envés, por lo demás, similares a $A$. arizonica. La mayoría de las muestras presentan flores o frutos.

Durango: Sierra del Epazote, Rancho El Durangueño, 2423'0" N, 105 $01^{\prime} 06^{\prime \prime}$ W, S. González 6291 et al. (CIIDIR, IEB). Aguascalientes: $12 \mathrm{~km}$ al SW de La Congoja, mpio. San José de Gracia, J. Rzedowski y R. McVaugh 799 (ENCB); Sierra Fría, mpio. San José de Gracia, L. M. González V., J. A. Pérez de la R. y R. Ramírez 2779 (CHAPA, ENCB, IEB). Jalisco: base W de La Tetilla del Volcán de Tequila, L. M. González V. et al. 2313 (ENCB, IBUG); ibid., L. M. González V. 2770 (IEB, ENCB); ibid., L. M. González V. 2771 (CHAPA, ENCB); roca de La Tetilla, cima del Volcán de Tequila, mpio. Tequila, 2900 m, M. Cházaro y Patiño 7156 (CHAPA, IBUG, IEB, MEXU); cima del volcán de Tequila, sobre el macizo rocoso llamado la Tetilla, $A$. Rodríguez C. y L. Guzmán H. 682 (IBUG); faldas de La Tetilla del Volcán de Tequila, J. A. Pérez de la Rosa s.n. (IBUG); La Tetilla, cerro de Tequila, R. Ramírez Delgadillo y J. A. Pérez de la Rosa 414 (IEB); ibid., R. Ramírez Delgadillo y J. A. Pérez de la Rosa 417 (IBUG); Tetilla del cerro de Tequila, R. Guzmán Mejía 737 (IBUG); La Tetilla, volcán de Tequila, S. Zamudio y E. Carranza 9265 (IEB, MEXU); cima del cerro Volcán de Tequila, mpio. Tequila, M. Cházaro et al. 4612 (IBUG, IEB); cerro de Tequila, en la parte alta, Grupo $1 D$ s.n. (IBUG); cerro de Tequila, ladera exp. N, mpio. Tequila, S. Carvajal Hernández 552 (IBUG); volcán de Tequila, camino estación de microondas - La Tetilla, L. M. González V., R. Ramírez Delgadillo y J. A. Pérez de la Rosa 3534 (IBUG); estación de microondas, cerro de Tequila, mpio. Tequila, bosque de Quercus-Pinus, G. Vázquez Prado 87 (IBUG).

Arbutus occidentalis $\mathbf{x}$ A. tessellata. Son plantas de 0.7-2 m con corteza teselada a semiteselada, peciolos con abundantes tricomas glandulares hasta de $2 \mathrm{~mm}$ de longitud y flores amarillo verdosas, lo que revela la relación con A. tessellata. El 
porte bajo, las hojas coriáceas y las inflorescencias reducidas indican que se trata de híbridos con A. occidentalis. Se conocen de Jalisco, entre los 2750 y $2800 \mathrm{~m}$.

Jalisco: Base W de La Tetilla del cerro de Tequila, L. M. González Villarreal 2315 (IBUG); ibid., L. M. González Villarreal 2767 y J. A. Pérez de la Rosa (IEB); Volcán de Tequila, camino estación de microondas - La Tetilla, mpio. Tequila, L. M. González V., R. Ramirez Delgadillo y J. A. Pérez de la Rosa 3531 (IBUG).

Arbutus occidentalis $\mathbf{x}$ A. bicolor (Fig. 6 D, 4 E). Son arbustos ya sea de 0.5 a $2.5 \mathrm{~m}$ de alto, con ramillas del segundo año gruesas (3 $\mathrm{mm}$ o más de grosor), lisas y con cubierta glauca o exfoliante en laminillas amplias (hasta de más de $1 \mathrm{~cm}$ ), o arbustos de 0.15 a $0.25 \mathrm{~m}$ con ramillas delgadas y envés de las hojas densamente canescente (por ejemplo en Palmer 195); en ambos casos la pubescencia del envés es de tricomas cortos, contortos (irregularmente retorcidos) y uniformemente distribuidos sobre la superficie (como en A. bicolor) (Fig. 6 D, 4 E); haz ya sea opaco (como en $A$. bicolor) o lustroso (como en $A$. occidentalis) pero en este último caso las hojas son ovadas y hasta de $4.7 \mathrm{~cm}$ de ancho revelando la influencia de $\mathrm{A}$. bicolor, aunque en ningún caso se observa la densa glandulosidad característica de esta última especie. Estos híbridos son abundantes y forman poblaciones en las que se mantienen sus características morfológicas, lo que deja abierta la posibilidad de que representen poblaciones genéticamente diferenciadas. Se conocen de Durango y el sur de Chihuahua, entre los 2440 y 2700 m de altitud.

Chihuahua: Sierra Mohinora, mpio. Guadalupe y Calvo, Gentry, Correll and Arguelles 17997 (US). Nayarit: 97 km WNW of Huejuquilla El Alto, rd. to Jesús María, 2410 m, Breedlove 61445 (CAS, MEXU). Durango: 3 km de El Huacal por el camino a El Tarahumar, mpio. Tepehuanes, M. González 2446 (CHAPA, CIIDIR, MEXU-2); $21 \mathrm{~km}$ al W de Tepehuanes, brecha a Tabahueto, mpio. Tepehuanes, suelo blanco calizo, en fruto, P. Tenorio L. 4173, con R. Torres C., E. Torrecillas $N$. (CIIDIR, MEXU); Los Potrillos, mpio. Tepehuanes, suelo somero, pedregoso, O. Bravo 460 (CHAP, CIIDIR); Quebrada Honda, mpio. Topia (la etiqueta indica erróneamente "San Ramón", la localidad en la que Palmer había colectado tres días antes), E. Palmer 195 (US); Subcuenca Santiago Bayacora, El Puerto del Juste, mpio. Durango, 2332'17" N, 104²'06" W, J. Acevedo Herrera 151 (CIIDIR).

Arbutus occidentalis $\mathbf{x}$ A. aff. xalapensis (Fig. 4 F). Algunas plantas de Durango y Jalisco son arbustos que varían entre 0.1 y $2.5 \mathrm{~m}$ de alto, ya sea con ramillas del segundo año gruesas y lisas (lo que revela exfoliación en placas amplias) o con ramillas del segundo año delgadas $(2-3 \mathrm{~mm})$ pero rugosas, lo que en ambos casos 
sugiere introgresión de una especie arbórea de Arbutus con A. occidentalis; presentan hojas pubescentes al menos en el envés, a veces flocosa como en A. xalapensis (Fig. 4 F), ovadas a elípticas, de forma similar a las de $A$. occidentalis pero con frecuencia más grandes, u ovado oblongas. Las características de $A$. occidentalis se manifiestan en el hábito arbustivo, el margen de las hojas fina y uniformemente aserrado y/o púrpura y las inflorescencias reducidas. El envés de las hojas jóvenes presenta pubescencia blanquecina (no ferrugínea como en $A$. mollis), a excepción de la colecta de Tenorio 822). Algunas de estas plantas forman poblaciones amplias y probablemente representan una entidad taxonómica distinta. Se requieren estudios más detallados para definir su situación. Se conocen de elevaciones entre los 2260 y $2980 \mathrm{~m}$.

Durango: El Tarahumar, arroyo del Cristo, al W del vivero, mpio. Tepehuanes, S. Acevedo 881 (CIIDIR, IEB, MEXU); Bajío de Los Arcos, por el camino de El Huacal a Quebrada Honda, mpio. Tepehuanes, M. González 2496 (CIIDIR, IEB, MEXU); El Espíritu, $2 \mathrm{~km}$ de Las Cruces, por el camino de El Huacal a Quebrada Honda, mpio. Tepehuanes, M. González 2498 (CHAPA, CIIDIR, IEB); paraje Chamacueros, $30 \mathrm{~km}$ al W de Mesa de Návar, mpio. Tepehuanes, $A$. (Benitez) Paredes y O. Bravo 399 (CHAP, CIIDIR); Cuevecillas, atrás del campamento de la UAF Topia, mpio. Canelas, bosque de pino encino, A. Benitez Paredes 2334 (CHAP,

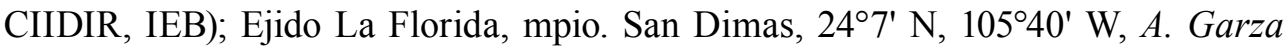
Herrera y col. s.n. (CIIDIR); El Tapextle, mpio. Pueblo Nuevo, 2000 m, en la barranca, muy abundante, P. Tenorio L. 822, con C. Romero de T. (CIIDIR, MEXU); Tapextle, $18 \mathrm{~km}$ de la desv. a la Mina de San Luis, R. Hernández M. 7645 y P. Tenorio (MEXU); ejido Navajas, inicio de vereda a cañada de los cedros, pasando Los Bajíos, 2349'55" N, 10507'39" W, S. González 6296 con E. Vega, R. Carrillo, P. Graciano (CIIDIR); ibid., S. González 6297 con E. Vega, R. Carrillo, P. Graciano (CIIDIR, IEB, MEXU); Predio Las Bayas de la UJED, arroyo La Tecolota, 23⒉ N, 104'50' W, A. García 1214 con M. Pinedo (CIIDIR, IEB); Francisco I. Madero (Pajaritos), 2244'46" N, 104'15'48" W, S. González 6464 con P. Peterson (CIIDIR, IEB, MEXU); ibid., S. González 6468, P. M. Peterson (CIIDIR, IEB); Jalisco: 5 km adelante del rancho Las Gallinas, $\mathrm{km} 40$ de brecha Bolaños-Tenzompa, mpio. Mezquitic, R. Ramírez Delgadillo et al. 1197 (IBUG); $10 \mathrm{~km}$ al N de Bajío Los Amoles, Mezquitic, A. Flores M. et al. 2270 (IBUG, MEXU)

Adicionalmente a los componentes de los complejos de A. mollis y A. occidentalis, dos especies de Arbutus que usualmente se desarrollan como árboles ocasionalmente llegan a presentar formas arbustivas: A. tessellata (arbustos coloniales postrados de 0.2 a $0.4 \mathrm{~m}$ de alto) y A. xalapensis var. texana (Buckley) A. Gray (arbustos 
postrados o erectos de 0.4 a $2 \mathrm{~m}$ de alto). Otras plantas para las que se registra hábito arbustivo, corresponden a rebrotes a partir de bases de árboles quemados o talados, por ejemplo varias colectas de A. arizonica, así como Arbutus aff. xalapensis de Jalisco: Las Capillas, mpio. se Cuautitlán, bosque mesófilo, 2800 m, L. M. González V. y J. A. Pérez de la Rosa 2494 (IBUG).

Para esclarecer satisfactoriamente las interacciones entre los componentes de los complejos de Arbutus mollis y A. occidentalis, al igual que las del complejo de $A$. xalapensis se requieren estudios poblacionales más detallados usando herramientas citogenéticas, fitoquímicas o moleculares.

\section{AGRADECIMIENTOS}

Agradecemos al Dr. Jerzy Rzedowski su orientación para dilucidar la identidad de A. mollis, al Dr. Paul D. Sørensen por compartir su amplia experiencia sobre el grupo, al Biól. Miguel Medina C. por la búsqueda de ejemplares en el herbario ENCB, a la M. en C. Lorena López, Dr. Jorge A. Tena, Srita. Daniela Corral, L.D.G. Violeta Espinosa C. y M. en C. María Eugenia Molina P. por su ayuda en diferentes fases del trabajo, a la Dra. Silvia Espinosa y la M. en C. Berenit Mendoza por las fotografías al microscopio electrónico de barrido, a la M. en C. Martha Beatriz Campos por el mapa, y a los encargados de los herbarios CAS, CHAP, CHAPA, CIIDIR, ENCB, IBUG, IEB, MEXU, MICH, NY, P, QMEX y US por el préstamo de materiales $\mathrm{y} / \mathrm{o}$ facilidades para consulta. Las sugerencias de dos revisores anónimos permitieron mejorar el manuscrito. Al Comité Técnico de Prestaciones a Becarios del Instituto Politécnico Nacional se agradece el apoyo para concluir este trabajo y a la Comisión de Operación y Fomento de Actividades Académicas por los estímulos a la investigación. El trabajo fue desarrollado con apoyo económico del Instituto de Ecología, A.C. (Cuenta 902-03), del Instituto Politécnico Nacional (proyecto 20120650), del Consejo Nacional de Ciencia y Tecnología y de la Comisión Nacional para el Conocimiento y Uso de la Biodiversidad.

\section{LITERATURA CITADA}

Diggs, G. M. 1995. Comarostaphylis Zuccarini. In: Luteyn, J. L. (ed.). Ericaceae Part II: the superior-ovaried genera. Flora Neotropica, Monograph 66. New York Botanical Garden. New York, USA. pp. 146-193. 
González-Elizondo, M. S. y M. González-Elizondo. 1992. El género Arbutus (Ericaceae) en la Sierra Madre Occidental. Consideraciones sobre su taxonomía y distribución. Bol. Inst. Bot. Univ. Guadalajara 1(2): 39-41.

González-Elizondo, M. S., M. González-Elizondo y P. D. Sørensen. 2012. Arbutus bicolor (Ericaceae), a new species from Mexico. Acta Bot. Mex. 99: 55-72.

González-Villarreal, L. M. 1990. Las Ericáceas de Jalisco, México. Colección Flora de Jalisco. Instituto de Botánica, Universidad de Guadalajara. Guadalajara, México. 140 pp.

Hausdorf, B. 2011. Progress toward a general species concept. Evolution 65(4): 923-931.

Hileman, L. C., M. C. Vasey y V. T. Parker. 2001. Phylogeny and biogeography of the Arbutoideae (Ericaceae): Implications for the Madrean-Tethyan hypothesis. Syst. Bot. 26(1): 131-143.

Kunth, C. S. 1818(1819). Arbutus mollis. In: Humboldt, A., A. Bonpland \& C. S. Kunth. Nov. Gen. Sp. 3: 280.

Lexer, C. y A. Widmer. 2008. The genic view of plant speciation: recent progress and emerging questions. Phil. Trans. R. Soc. Lond. B 363: 3023-3036.

Luteyn, J. L. 2009. Arbutus, Flora Mesoamericana 4(1): 418.

Mallet, J. 2005. Hybridization as an invasion of the genome. Trends Ecol. Evol. 20: 229-237.

Mallet, J. 2008. Hybridization, ecological races, and the nature of species: empirical evidence for the ease of speciation. Phil. Trans. R. Soc. Lond. B 363: 2971-2986.

McDade, L. A. 1995. Species concepts and problems in practice: Insight from botanical monographs. Syst. Bot. 20(4): 606-622.

McVaugh, R. y T. J. Rosatti. 1978. A new species of Arbutus (Ericaceae) from western Mexico. Contr. Univ. Michigan Herb. 11: 301-304.

Roe, K. E. 1971. Terminology of hairs in the genus Solanum. Taxon 20(4): 501-508.

Sørensen, P. D. 1987. Arbutus tessellata (Ericaceae), new from Mexico. Brittonia 39: 263267.

Sørensen, P. D. 1995. Arbutus Linnaeus. In: Luteyn, J. L. (ed.). Ericaceae Part II: The superior-ovaried genera. Flora Neotropica, Monograph 66. New York Botanical Garden. New York. USA. pp.194-221.

Soubani, E. 2010. Systematics, phylogeography and multiple origins of morphs in two species complexes belonging to Cistaceae, Helianthemum oelandicum and H. nummularium. Doctoral Dissertation. Lund University. Suecia. consultado el 31 de Marzo de 2011. http://lup.lub.lu.se/luur/download?func $=$ downloadFile\&recordOId=1670264\&fileO $\mathrm{Id}=1670378$

Standley, P. C. 1924. Arbutus. Trees and shrubs of Mexico. Contr. U.S. Natl. Herb. 23: 10991100.

Templeton, A. R. 1998. Species and speciation. Geography, population structure, ecology, and gene trees. In: Howard, D. J. y S. H. Berlocher (eds.). Endless forms: species and speciation. Oxford University Press. New York, USA. pp. 32-43. 